\title{
Advanced Reactor Siting Policy Considerations
}

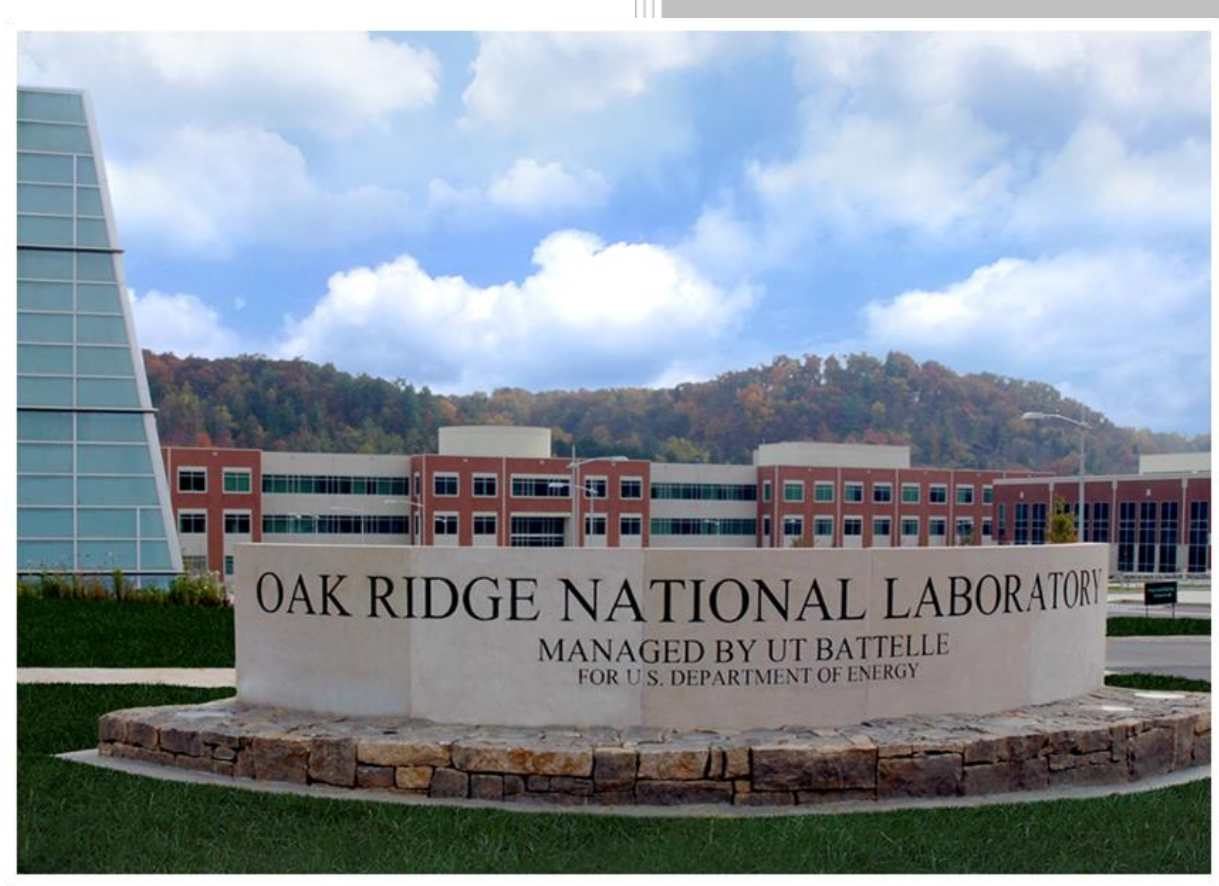

Approved for public release.

Distribution is unlimited.
R. J. Belles
G. F. Flanagan
R. E. Hale
D. E. Holcomb
A. J. Huning
W. P. Poore

June 2019 


\title{
DOCUMENT AVAILABILITY
}

Reports produced after January 1, 1996, are generally available free via US Department of Energy (DOE) SciTech Connect.

Website www.osti.gov

Reports produced before January 1, 1996, may be purchased by members of the public from the following source:

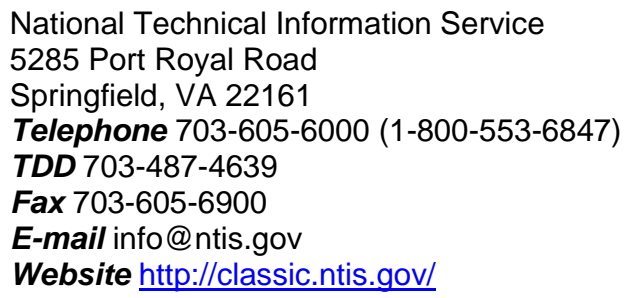

Reports are available to DOE employees, DOE contractors, Energy Technology Data Exchange representatives, and International Nuclear Information System representatives from the following source:

Office of Scientific and Technical Information

PO Box 62

Oak Ridge, TN 37831

Telephone 865-576-8401

Fax 865-576-5728

E-mail reports@osti.gov

Website http://www.osti.gov/contact.html

\begin{abstract}
This report was prepared as an account of work sponsored by an agency of the United States Government. Neither the United States Government nor any agency thereof, nor any of their employees, makes any warranty, express or implied, or assumes any legal liability or responsibility for the accuracy, completeness, or usefulness of any information, apparatus, product, or process disclosed, or represents that its use would not infringe privately owned rights. Reference herein to any specific commercial product, process, or service by trade name, trademark, manufacturer, or otherwise, does not necessarily constitute or imply its endorsement, recommendation, or favoring by the United States Government or any agency thereof. The views and opinions of authors expressed herein do not necessarily state or reflect those of the United States Government or any agency thereof.
\end{abstract}


Reactor and Nuclear Systems Division

\title{
ADVANCED REACTOR SITING POLICY CONSIDERATIONS
}

\author{
R. J. Belles \\ G. F. Flanagan \\ R. E. Hale \\ D. E. Holcomb \\ A. J. Huning \\ W. P. Poore
}

Date: June 2019

Prepared by

OAK RIDGE NATIONAL LABORATORY

Oak Ridge, TN 37831-6283

managed by

UT-BATTELLE, LLC

for the

US DEPARTMENT OF ENERGY

under contract DE-AC05-00OR22725 



\section{CONTENTS}

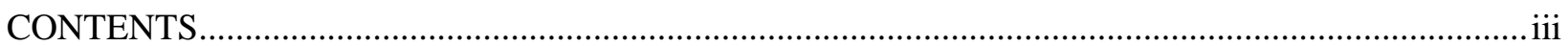

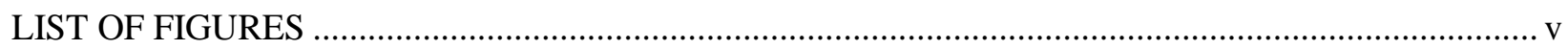

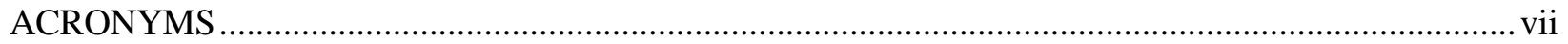

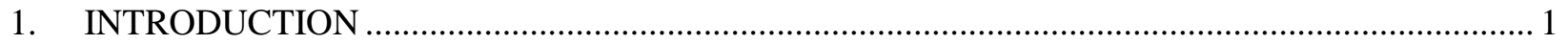

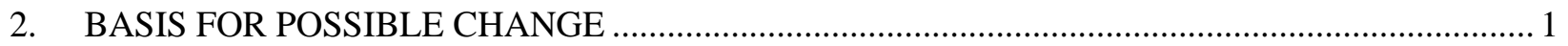

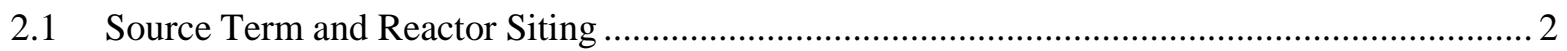

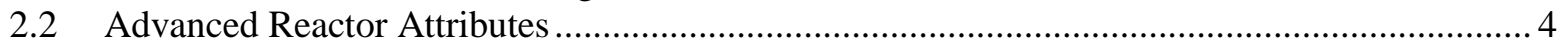

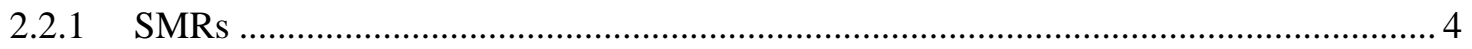

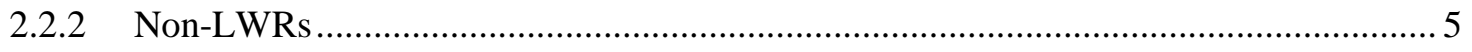

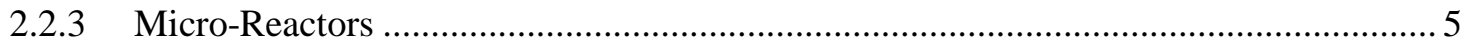

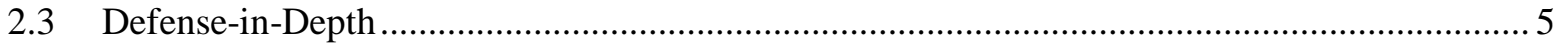

2.4 Fulfillment of Fundamental Safety Functions Through Passive Technologies ........................ 7

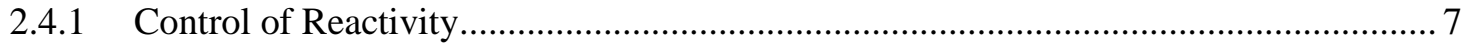

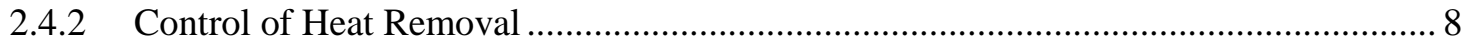

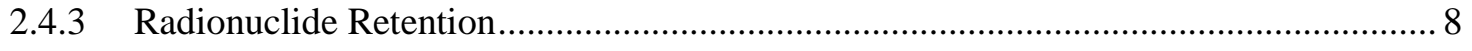

2.5 Below-Grade Siting as an Alternative for Distance .............................................................. 9

2.6 The NUREG-1537 Siting Approach …............................................................................. 10

2.7 Changes in the Public Views of Risk Since the Development of the Commissions'

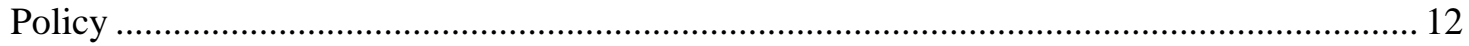

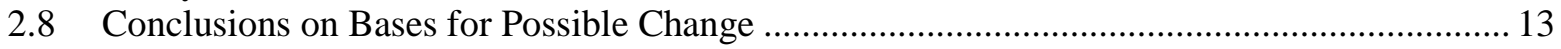

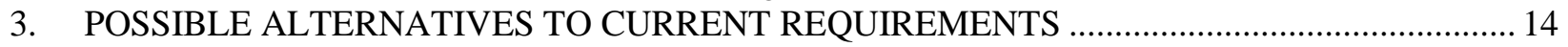

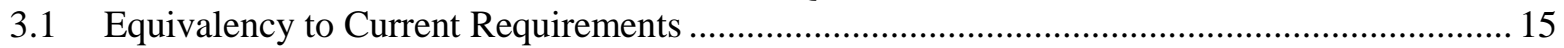

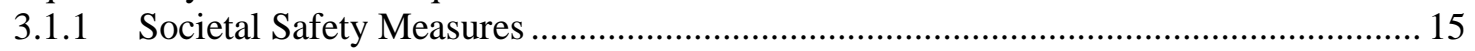

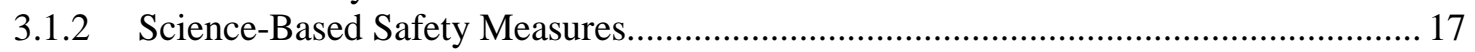

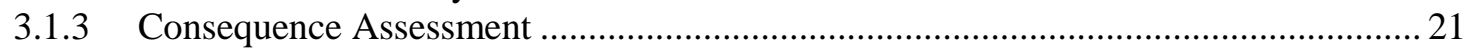

3.2 Engineered Safety Feature Considerations …............................................................... 22

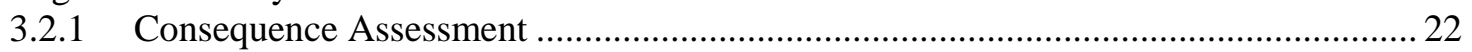

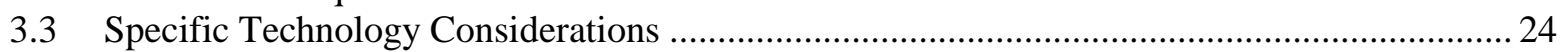

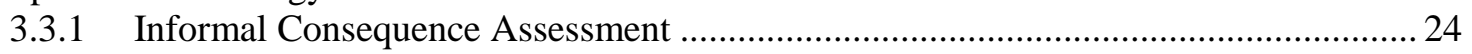

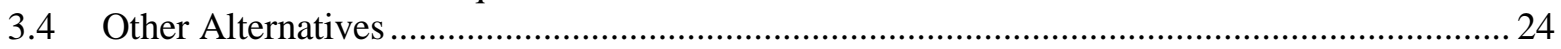

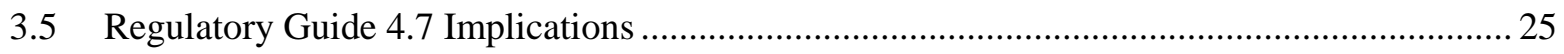

3.6 Conclusions on Possible Alternatives to Current Requirements............................................ 25

4. DOE AND INDUSTRY (Nuclear Energy Institute [NEI]) INCENTIVES TO IMPROVE

SITING CRITERIA ...................................................................................................... 27

4.1 Do Possible Guidance Changes Impact the Siting Opportunity for Advanced Reactor

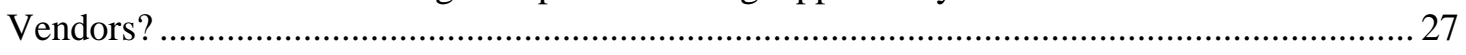

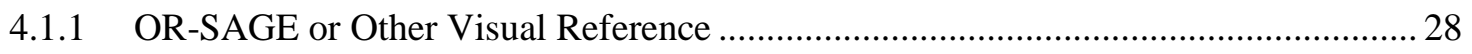

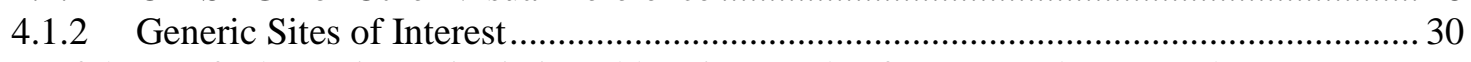

4.2 Usefulness of Alternative Criteria in Addressing Goals of Doe, Vendors, or Other

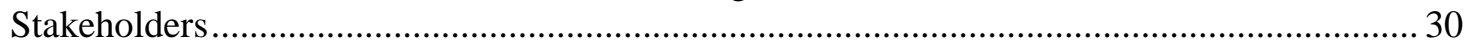

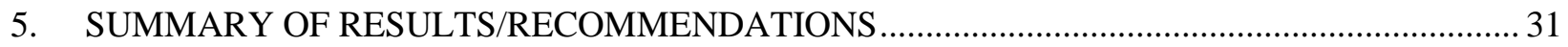

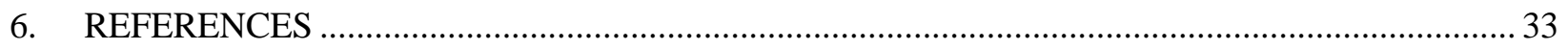

APPENDIX A. CURRENT SITING CRITERIA - REGULATIONS AND GUIDANCE ..................... A-1

A.1. Summary of Regulations Related to Siting ....................................................................

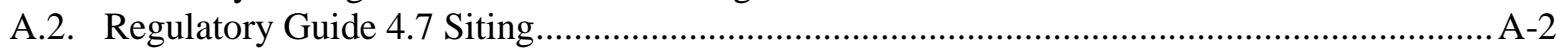

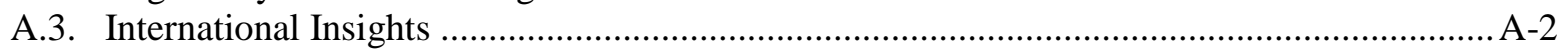

A.3.1 IAEA Site Evaluations (IAEA NS-R-3) - Requirement ………............................... A-3

A.3.2 IAEA Siting Recommendations (IAEA NG-T-3.7) - Guidance ............................... A-3 


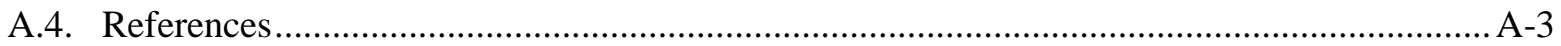

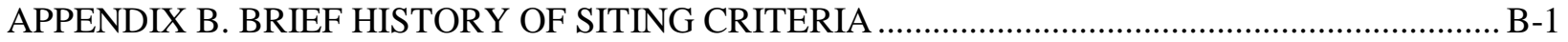

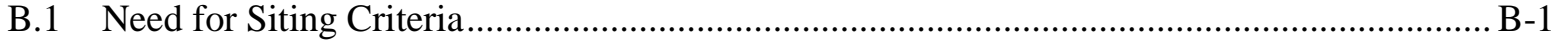

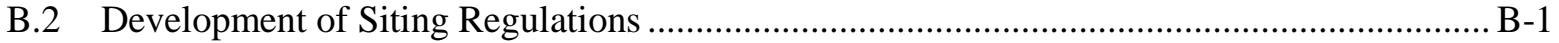

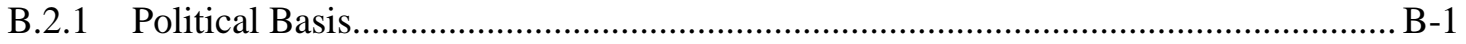

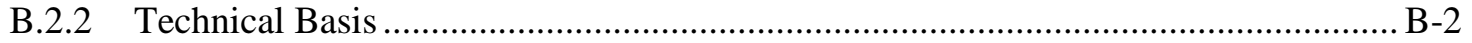

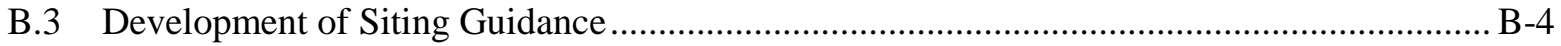

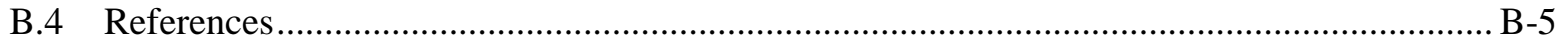




\section{LIST OF FIGURES}

Figure $\quad$ Page

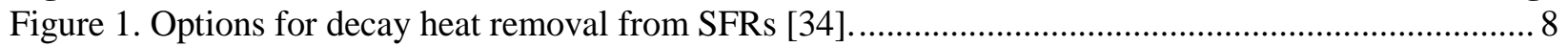

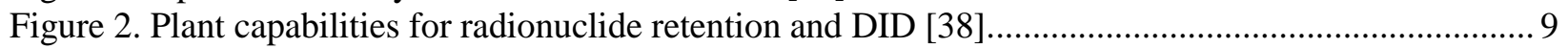

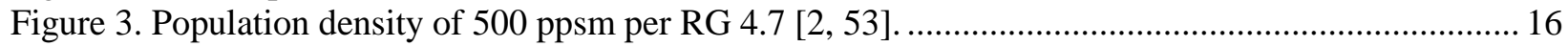

Figure 4. Comparison of dose intensity for dose D, .5D, .1D, and .05D to 20 miles. ........................... 18

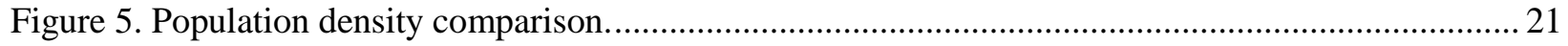

Figure 6. Sample population density calculations for 2030 around Kansas City. ....................................22

Figure 7. Excluded population density (500 ppsm at 20 miles) .........................................................2 28

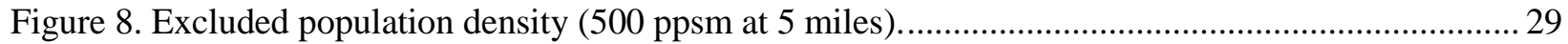

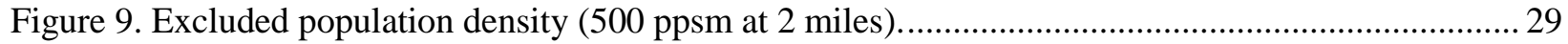

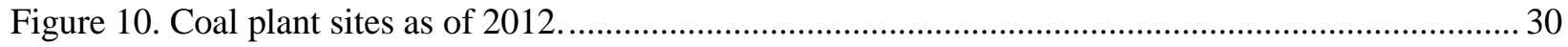

\section{LIST OF TABLES}

Table $\quad$ Page

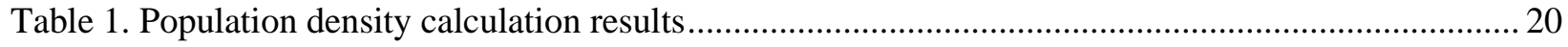

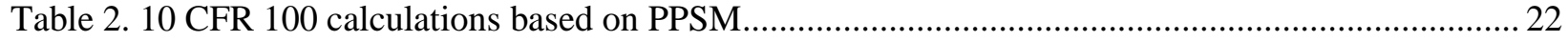

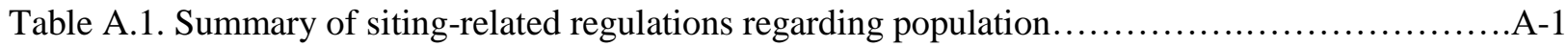

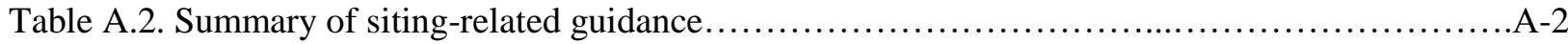





\section{ACRONYMS}

\begin{tabular}{|c|c|}
\hline ACRS & Advisory Committee on Reactor Safeguards \\
\hline AEA & Atomic Energy Act \\
\hline $\mathrm{AEC}$ & Atomic Energy Commission \\
\hline ASME & American Society of Mechanical Engineers \\
\hline BPVC & Boiler and Pressure Vessel Code \\
\hline BWR & boiling water reactor \\
\hline CFR & Code of Federal Regulations \\
\hline DBA & design basis accident \\
\hline DID & defense-in-depth \\
\hline DOE & US Department of Energy \\
\hline DRACS & Direct Reactor Auxiliary Cooling System \\
\hline EAB & exclusion area boundary \\
\hline EPZ & emergency planning zone \\
\hline FSF & fundamental safety function \\
\hline GIS & geographic information system \\
\hline IAEA & International Atomic Energy Agency \\
\hline IRACS & Immediate Reactor Auxiliary Cooling System \\
\hline JCAE & Joint Committee on Atomic Energy \\
\hline LOCA & loss-of-coolant accident \\
\hline LPZ & low population zone \\
\hline LWR & light water reactor \\
\hline NASA & National Aeronautics and Space Administration \\
\hline NEI & Nuclear Energy Institute \\
\hline NGNP & Next Generation Nuclear Plant \\
\hline NIST & National Institute of Standards and Technology \\
\hline Non-LWR & non-light water reactor \\
\hline NPP & nuclear power plant \\
\hline NRC & US Nuclear Regulatory Commission \\
\hline ORNL & Oak Ridge National Laboratory \\
\hline OR-SAGE & Oak Ridge Siting Analysis for power Generation Expansion \\
\hline PPSM & person per square mile \\
\hline PRA & probabilistic risk assessment \\
\hline PRACS & Primary Reactor Auxiliary Cooling System \\
\hline PRDC & Power Reactor Development Company \\
\hline PWR & pressurized water reactor \\
\hline RG & regulatory guide \\
\hline RVACS & Reactor Vessel Auxiliary Cooling System \\
\hline SFR & sodium fast reactor \\
\hline SGACS & Steam Generator Auxiliary Cooling System \\
\hline SMR & small modular reactor \\
\hline SOARCA & state-of-the-art reactor consequence analysis \\
\hline SSC & systems, structures, and components \\
\hline TEDE & total effective dose equivalent \\
\hline TID & technical information document \\
\hline TS & technical specification \\
\hline TVA & Tennessee Valley Authority \\
\hline VCCS & Vessel Cavity Cooling System \\
\hline
\end{tabular}





\section{INTRODUCTION}

This report describes considerations for and challenges to revising the US Nuclear Regulatory Commission (NRC) guidance regarding population for siting an advanced reactor. Current regulations in 10 Code of Federal Regulations (CFR) Part 100, Reactor Site Criteria, and guidance support in Regulatory Guide (RG) 4.7, Revision 3, General Site Suitability Criteria for Nuclear Power Stations, are focused on large light water reactors (LWRs), addressing the distance that a nuclear reactor should be sited from a densely populated center.

This report analyzes the alternatives to using a formula distance as the primary figure of merit for siting small modular reactors (SMRs) or non-light water reactors (non-LWRs). Some reactor vendors use a business plan that sites reactors close to an industrial partner to supply heat or to back-fit a reactor at a fossil plant site to take advantage of existing infrastructure. Factors such as smaller source terms (fission product release to the environment), passive safety systems, advances in barrier technology, advances in simulation and modeling, and improved understanding of societal risk may allow for siting these types of reactors closer to densely populated centers than has historically been accepted for large LWRs.

\section{BASIS FOR POSSIBLE CHANGE}

In a draft whitepaper on siting advanced reactors, NRC staff notes [1] the following based on Commission expectations:

SMRs and non-LWRs might have risk profiles significantly lower than the Commission's
Safety Goals and the potential radiological releases from SMRs and non-LWRs are
expected to be smaller than the current fleet of large LWRs. Therefore, prospective
applicants may consider proposing exclusion areas and low population zones associated
with SMRs and non-LWR sites that are reduced in size compared to those established for
large LWRs. As a result, these sites could be located closer to densely populated centers,
if one were to focus exclusively on the criteria related to potential radiological doses to
individuals.

However, current siting guidance [2] uses a combination of distance and population density limits as a surrogate for addressing potential radiological doses to individuals. This guidance is based on (1) a lack of experience with LWR technology, (2) a lack of data on the reliability of safety systems, and (3) the need for public safety when nuclear power plants (NPPs) were becoming a more commonplace option for power generation [3].

This paper reviews the evolution of reactor design, safety, and licensing, and how it has impacted siting approaches relative to population centers. Almost 40 years ago, NRC staff prepared several NUREG reports that evaluated reactor accident source terms. Since it was assumed that significant portions of the noble gases would be released following certain accidents, siting discussions regarding societal risk were initiated $[4,5,6]$. After the terrorist attacks against the United States on September 11, 2001, NRC staff began conducting research to better evaluate a potential radioactive release following a severe NPP accident. The insights gained from NRC's research project are considered herein for siting SMRs and advanced non-LWRs. This analysis is followed by a discussion of advanced reactor attributes, including how they differ from the attributes of current LWR designs and their relevance to a reassessment of siting guidance. The extent to which advanced reactor attributes such as defense-in-depth (DID), passive safety systems, seismic isolation, and below-grade construction are included in a new approach may influence siting guidance for these reactors. Guidance for non-power reactors is separate and distinct from current LWR siting guidance, which should be explored for applicability to advanced reactors. Finally, societal 
views of risk have evolved over the last 40 years, which could also influence siting guidance for advanced reactors.

\subsection{SOURCE TERM AND REACTOR SITING}

At the time of the original licensing and siting for the currently operating reactors, the licensing siting dose analysis to support exclusion area boundary (EAB) size, low population zone (LPZ) size, and source-term guidance for the maximum hypothetical accident was given in RG 1.3 and RG 1.4 [7,8], as well as NUREG-0800 [9], 15.6.5 Appendices—all of which referenced TID-14844, Calculation of Distance Factors for Power and Test Reactor Sites [10]. For siting, TID-14844 and 10 CFR 100 considered the maximum hypothetical accident to be a major accident involving significant core damage that is typically postulated to occur in conjunction with a large loss-of-coolant accident (LOCA). RG 1.3 and RG 1.4 assumed $25 \%$ of the equilibrium radioactive iodine inventory developed from maximum full power operation of the core should be assumed to be immediately available for leakage from the primary reactor containment. In addition, 100\% of the equilibrium radioactive noble gas inventory developed from maximum full power operation of the core should be assumed to be immediately available for leakage from the reactor containment. The primary reactor containment should be assumed to leak at the leak rate incorporated or to be incorporated as a technical specification requirement at peak accident pressure for the first 24 hours, and at 50 percent of this leak rate for the remaining duration of the accident. TID-14844 supports reactor siting and is part of the basis for the original promulgation of 10 CFR Part 100 and may still be in the current licensing basis for some reactors.

For analytical purposes, following the assessment of the accident at Three Mile Island Unit 2 in 1979, NRC issued several NUREG reports that discuss reactor accident source terms and release. NUREG0771, Regulatory Impact of Nuclear Reactor Accident Source Term Assumptions, clarifies the current reactor accident source term assumptions [4]. A companion report, NUREG-0772, Technical Basis for Estimating Fission Product Behavior during LWR Accidents, was developed to present investigation of the generation, transport, and attenuation of aerosols, particularly iodine [5]. The objective of this report was to assess the effect on fission product release estimates and to estimate the performance of engineered safety features under beyond-design-bases accident conditions. NUREG-0773, The Development of Severe Reactor Accident Source Terms: 1975-1981, provides a detailed description of considerations that informed the development of the spectrum of reactor accident source terms for LWR designs, including fission product release fractions and release characteristics [6]. The reports note that the models used had known deficiencies which would tend to overestimate the magnitudes of releases. These NUREGs represent the best source term studies that were available at the time, and they served as the basis for much of the early regulatory guidance in this area. These NUREGs are referenced in a 1982 siting study prepared by Sandia National Laboratory, NUREG/CR-2239, Technical Guidance for Siting Criteria Development [11].

NUREG/CR-2239 was developed to provide technical guidance for siting NPPs regarding the following factors:

1. Standoff distances of plants from offsite hazards

2. Criteria for population density and distribution surrounding proposed future sites

The external hazards considered in the 1982 report include aircraft, hazardous chemicals, dams, faults, adjacent NPPs, tsunamis, meteorite impact, etc. This 1982 study concludes that none of the external hazards considered are suitable for treatment by fixed standoff distances and that sufficient methods were in place to evaluate the risk for most types of hazards. 
The population density and distribution guidance in the 1982 report focuses on consequences of possible plant accidents at existing sites based on existing population distribution characteristics. Population distributions at existing sites were examined to provide perspective on demographic characteristics and to determine whether there had been trends with time or regional differences in site selection. The report notes that the maximum 20 -mile population density observed (1982 data) was 710 people per square mile (ppsm), and the peak sector population density (22.5 degrees) was as high as 4,500 ppsm. Based on information on accident fission product release that was available at the time, the study assumed that $65 \%$ of the core inventory of ${ }^{137} \mathrm{Cs}$ and $45 \%$ of the ${ }^{131} \mathrm{I}$ would be released after a severe accident and came to the following conclusions regarding accident consequences:

- Early fatalities are very sensitive to source term magnitude

- Weather conditions at the time of a large release will have a substantial impact on the health effects caused by that release

- The distances to which consequences might occur depend principally upon source term magnitude and meteorology

- Calculated consequences are very sensitive to site population distribution

- Early fatalities and early injuries can be significantly reduced by emergency response actions

- Smaller reactors pose lesser risks to the public than larger reactors

- Exclusion zones (unless very large) are unlikely to significantly reduce early health effects for very large core melt accidents. However, for smaller accidents, early health effects could be significantly mitigated by establishing exclusion zones of 1 to 2 miles

The 1982 study does not propose specific population siting guidance. However, the study notes that while reactor siting near low population densities is desirable from the perspective of societal risk, the risk must be balanced with site availability. Site availability factors could include work force and infrastructure, along with more traditional factors such as seismicity, topography, groundwater, etc.

Since the publication of TID-14844 in 1962, significant advances have been made in understanding the timing, magnitude, and chemical form of fission product releases from severe nuclear power plant accidents. NUREG-1465, Accident Source Terms for Light-Water Nuclear Power Plants [12], applies this improved understanding by "providing more realistic estimates of the source term release into containment, in terms of timing, nuclide types, quantities, and chemical form, given a severe core-melt accident." NUREG-1465 was developed after it was observed that relatively small amounts of iodine were released following the Three Mile Island Unit 2 accident. Subsequently, 10 CFR 50.67, Accident Source Term, was published in the Federal Register in December 1999 to provide a regulatory means for an alternate accident source term to be applied to the design of future LWRs. RG 1.183, Alternative Radiological Source Terms for Evaluating Design Basis Accidents at Nuclear Power Reactors [13], was then issued in 2000 to support 10 CFR 50.67, allowing operators of then current LWRs to choose to revise their licensing basis source term. SMRs and non-LWRs will likely propose mechanistic source term analyses to evaluate public dose and siting instead of using TID-14844 or RG 1.183. SECY-93-0092 [14] defined a mechanistic source term as:

... the result of an analysis of fission product release based on the amount of cladding damage, fuel damage, and core damage resulting from the specific accident sequences being evaluated. It is developed using best-estimate phenomenological models of the transport of the fission products from the fuel through the reactor coolant system, 
through all holdup volumes and barriers, taking into account mitigation features, and finally, into the environs.

In response to the terrorist attacks on September 11, 2001, requirements were implemented in 10 CFR 50.54(hh) for those applying to build new nuclear power reactors. These applicants were required to evaluate and establish mitigating actions for the loss of large plant areas due to fires and explosions. The NRC initiated a state-of-the-art reactor consequence analysis (SOARCA) research project to better evaluate radioactive release following a severe NPP accident. Modeling and simulation capabilities have progressed significantly since NUREG/CR-2239 was prepared. Likewise, operator training, inspection programs, emergency procedures, and emergency planning have all improved in the interim. The SOARCA project evaluated mitigated and unmitigated station blackout (SBO) scenarios for boiling water reactors (BWRs) and pressurized water reactors (PWRs). A PWR interfacing system loss-of-coolant accident (LOCA) was also evaluated. The report analyzes a worst-case unmitigated BWR scenario, a short-term SBO resulting in a release of less than $3 \%$ of the core inventory of ${ }^{137} \mathrm{Cs}$ and less than $12 \%$ of the ${ }^{131} \mathrm{I}$. The report also analyzes a worst-case unmitigated PWR scenario of an interfacing system LOCA that results in a release of less than $3 \%$ of the core inventory of ${ }^{137} \mathrm{Cs}$ and less than $15 \%$ of the ${ }^{131} \mathrm{I}$. These results represent considerable reductions in the release fractions compared to those presented in the 1982 siting study [15].

The SOARCA project demonstrated that improved modeling and simulation tools and techniques have evolved over time, and they can reduce the magnitude and uncertainty associated with predicted fission product release for certain defined LWR accident scenarios compared to previous predictions. However, the accident at Fukushima showed that an unforeseen worst-case accident (beyond design basis) can result in the release of a large percentage of LWR core cesium and iodine inventory. While modeling and simulation improve the predictive capability for designers and regulators, further investigation of advanced reactor attributes is warranted as a basis for possible alternatives to relying on formula distance and population density as the primary siting guidelines.

\subsection{ADVANCED REACTOR ATTRIBUTES}

Economics, niche markets, improved safety, and grid reliability are some of the issues driving the exploration of alternatives to large LWRs. The US Department of Energy (DOE) supports development of several advanced reactors types, including small modular reactors (SMRs), non-LWRs, and more recently, micro-reactors. These reactor types are addressed briefly in the sections below.

\subsubsection{SMRs}

SMRs are generally defined as machines that provide less than $300 \mathrm{MW}_{\mathrm{e}}$ [16]. Units may be operated individually or as part of a multi-module plant. Near-term SMRs are typically based on LWR technology with integrated components (steam generator, pressurizer, etc.) inside the reactor vessel.

Typical SMRs are designed such that they incorporate passive safety features that ultimately do not require offsite electricity, offsite water, or immediate operator action (hours/days versus minutes/seconds) to mitigate reactor design basis accidents (DBAs) [17]. Near-term SMRs with designs based on LWR technology typically have more coolant water per $\mathrm{kW}$ than large LWRs, which provides increased coping times following a DBA. SMRs are expected to have fewer pumps and valves and less piping, resulting in a lower aggregate probability of component failure. In addition, certain accidents, such as a large-break LOCA, are eliminated by design.

SMRs produce less heat and have a smaller source term compared to large LWRs. SMRs also have a smaller site footprint than large LWRs. Based on accident and dose analyses, these attributes could lead to 
a smaller exclusion area boundary $(\mathrm{EAB})$ and subsequently, a smaller low population zone. This is consistent with the conclusion of early studies on accident release, such as the 1982 Sandia siting study [11].

\subsubsection{Non-LWRs}

A non-LWR may be defined as an SMR, or it may be a larger reactor. Non-LWRs use a coolant other than water, and they may use alternate fuel forms. Typical technologies include gas-cooled reactors, liquid-metal-cooled reactors, molten-salt-fueled reactors, and molten-salt-cooled reactors.

Particle-based fuel forms such as those proposed for some gas-cooled reactor designs have higher melting temperatures and more robust barriers to radiation release than conventional LWR fuel. The likelihood of fuel melting and radiation being released is greatly reduced for such fuels, leading to increased coping time following a DBA [17].

Other non-LWRs such as liquid-metal-cooled reactors and molten salt reactors use coolants with low vapor pressure; therefore, they operate at low (near atmospheric) pressure with significant margin to coolant boiling. These reactor types lack the high operating pressure forcing mechanism in LWRs that disperses radiation outside containment barriers following an accident. Similar to SMRs, these attributes could lead to a smaller EAB and a smaller low population zone.

\subsubsection{Micro-Reactors}

A micro-reactor is a type of SMR with a small power rating and a very compact footprint. The DOE Office of Nuclear Energy defines microreactors as machines providing less than $20 \mathrm{MW}_{\text {th }}$ [18]. For example, Westinghouse advertises a micro-reactor that delivers $5 \mathrm{MW}_{\mathrm{e}},[19]^{1}$ which meets this definition at expected plant efficiencies. Individual units are expected to be used for remote power generation and micro-grid applications to match generation with demand. In addition to the technologies previously mentioned, heat-pipe reactors are among the designs being considered in this power range.

DOE maintains [18] that micro-reactors are not defined by their form or coolant. Rather, micro-reactors have three main features:

1. Factory fabricated

2. Transportable by truck, shipping vessel, airplane, or rail car

3. Self-regulating, not requiring many specialized operators, and utilizing passive safety systems to prevent any potential for overheating or reactor meltdown

In addition, micro-reactors are expected to have longer core lives and will require less spent fuel storage, possibly having the capability for complete reactor/fuel change out via a reactor power battery. Given the mission of these reactors, they will likely be located in close proximity to the communities or facilities they serve. This will require smaller EABs.

\subsection{DEFENSE-IN-DEPTH}

Defense-in-depth (DID) is a basic safety tenet that is interwoven into most NRC regulations. The NRC Basic Reference Glossary [20] defines DID as follows:

An approach to designing and operating nuclear facilities that prevents and mitigates accidents that release radiation or hazardous materials. The key is creating multiple

\footnotetext{
${ }^{1}$ Highest projected power output observed from several sources on micro-reactors.
} 
independent and redundant layers of defense to compensate for potential human and mechanical failures so that no single layer, no matter how robust, is exclusively relied upon. Defense-in-depth includes the use of access controls, physical barriers, redundant and diverse key safety functions, and emergency response measures.

As reflected in Table A.2 of this document, RG 4.7 [2] includes siting as a DID factor. As such, reactor distance from a population center is a siting element available to "reduce potential doses and property damage in the event of a severe accident."

NUREG-0880, Safety Goals for Nuclear Power Plants, explicitly includes siting as part of the definition for DID. DID involves careful quality assurance and control in plant design, construction, and operation; installation of backup systems to nullify the consequence of malfunctions in important plants systems; installation of engineered safety features to confine the consequences of certain postulated DBAs; and siting nuclear plants in areas of low population density and in locations that are not near natural or manmade hazards [21].

Dr. Tom Kress presented a paper regarding DID and probabilistic risk assessment (PRA) [22] at an Advisory Committee on Reactor Safeguards (ACRS) subcommittee meeting on August 27, 1997. A synopsis of the paper is included in NUREG/KM-009, Historical Review and Observations of DefenseIn-Depth [23]:

In the paper, Dr. Kress notes that during a good part of regulatory history the techniques and tools for determining risk were not well developed and risk measures were unavailable to the regulator. As a result, NRC developed a regulatory philosophy that it called defense-in-depth which can be viewed as providing balance among three "levels" of protection: preventing the initiation of accidents, stopping (or limiting) the progression of an accident, and providing for evacuation in the event of accidental release of fission products. Each of the three levels is to be implemented by providing multiple independent provisions to accomplish the desired function. He also notes that "balanced" does not mean "equal."

Regarding the three elements, he explains that the first (DID prevention) is implemented through provisions that include such things as quality in construction, quality assurance, inspections and maintenance, testing, and redundant and diverse emergency power supplies. The second element includes such concepts as multiple physical barriers, and redundant and diverse shutdown systems. The third element includes provisions for siting and the plans for evacuation and sheltering. This implementation of DID results in the idea that just about everything the NRC does is part of DID and it becomes difficult to separate out just those things that would be considered purely defense-in-depth requirements.

He [Dr. Kress] concludes that the PRA results can be considered a measure of the effectiveness of the overall implementation of DID.

The knowledge management NUREG [23] further notes:

Dr. Kress stated two concerns with DID: (1) DID does not constitute a precise definition in terms of risk assessment, and (2) a definition or criteria does not exist that allows for placing limits on DID. He proposes a definition of DID: "design defense-in-depth is a strategy of providing design features to achieve acceptable risk (in view of the uncertainties) by the appropriate allocation of the risk reduction to both prevention and 
mitigation." Dr. Kress proposed putting limits on DID by having risk acceptance criteria

that includes uncertainties, with quantifiable uncertainty coming out of a PRA and

unquantifiable uncertainty estimated by expert opinion.

This latter DID discussion by Dr. Kress has implications for advanced reactor siting. The discussion implies that, because advanced reactor designs tend to preclude or severely mitigate accident categories by design, and because passive safety systems tend to increase the reliability of an appropriate and successful accident response, there is margin to consider changes in siting distances without compromising the overall DID balance for public safety.

\subsection{FULFILLMENT OF FUNDAMENTAL SAFETY FUNCTIONS THROUGH PASSIVE TECHNOLOGIES}

Fundamental safety functions (FSFs) are defined by the International Atomic Energy Agency (IAEA) [24] as generic, technology-neutral safety functions common to any new reactor design. FSFs include (1) control of reactivity, (2) removal of the heat from the core, and (3) confinement of radioactive material. The concept of FSFs has been embraced by the industry as part of the efforts to modernize the technical requirements for licensing advanced non-LWRs [25] and is reflected in an NRC draft guidance document [26] on a risk-informed, performance-based licensing framework. Based on these generic FSFs, it is the applicant's responsibility to derive required safety functions applicable for their specific design.

The safety functions of current LWRs are primarily achieved through active systems, including an array of support systems. However, many advanced reactor designs include the use of passive systems instead of active systems to fulfill safety functions. Passive safety systems reduce the likelihood of an active component failure, so they are expected to be more reliable than active systems that perform a similar safety function. In addition, the consequences of design basis events and severe accidents may be significantly reduced due to enhancements in the radionuclide retention capabilities of advanced nuclear fuels. Therefore, a lower risk to the public may result from operation of advanced reactor designs that employ passive safety features and/or advanced nuclear fuel. Therefore, such technology advances may make it possible to relax reactor siting requirements with no increased risk to the public. This section describes some proposed examples of passive technologies which demonstrate enhancement of the FSFs compared to those of an active system.

\subsubsection{Control of Reactivity}

Reactivity control failure events are off-normal conditions in which heat generation exceeds the heat removal capability of the reactor. For existing LWRs, this can lead to fuel cladding failure and subsequent radionuclide retention failure if it is not quickly and actively controlled. Many new advanced reactors are being designed with fuel and core characteristics to significantly reduce the consequences of failure to actively control heat generation. This is achieved primarily through two passive safety features:

1. Strong negative temperature-based reactivity coefficients which inherently serve to reduce power and heat generation when positive reactivity is inserted

2. Large fuel temperature margin before any loss of radionuclide retention is induced by increased heat generation to accommodate reactivity excursion events

These passive features are common to many modular high-temperature gas [27,28], molten salt [29], liquid metal [30,31], and other novel reactor concepts [19,32]. In some advanced reactor concepts, passive reactivity control features, along with active control element systems such as $\mathrm{B}_{4} \mathrm{C}$ spheres, are being proposed as the principal means of controlling reactivity. Reactivity control has been identified 
previously as a potential issue [14] for advanced reactors. However, recently released RG 1.232, Guidance for Developing Principal Design Criteria for Non-Light Water Reactors [33], allows for consideration of a variety of control element systems.

\subsubsection{Control of Heat Removal}

Core heat removal is essential to any reactor design for any hypothetical accident or event. Passive heat removal systems are expected to be more reliable than similar active systems that depend on emergency power backups. The core melt events at the Fukushima reactors were initiated by the long-term loss of offsite and onsite electric power systems.

Passive heat removal systems generally rely on a combination of natural convection, radiation, and conduction as mechanisms for heat transport from the core to the ultimate heat sink. Such systems provide an extended accident response window for the operating crew. There are many different types of passive heat removal systems being proposed. Several passive decay heat removal system options for a sodium fast reactor (SFR) are shown in Figure 1 [34]. These decay heat removal options represent options in other advanced reactor designs and may be based on heat transfer to air, water, gas, or other fluids.

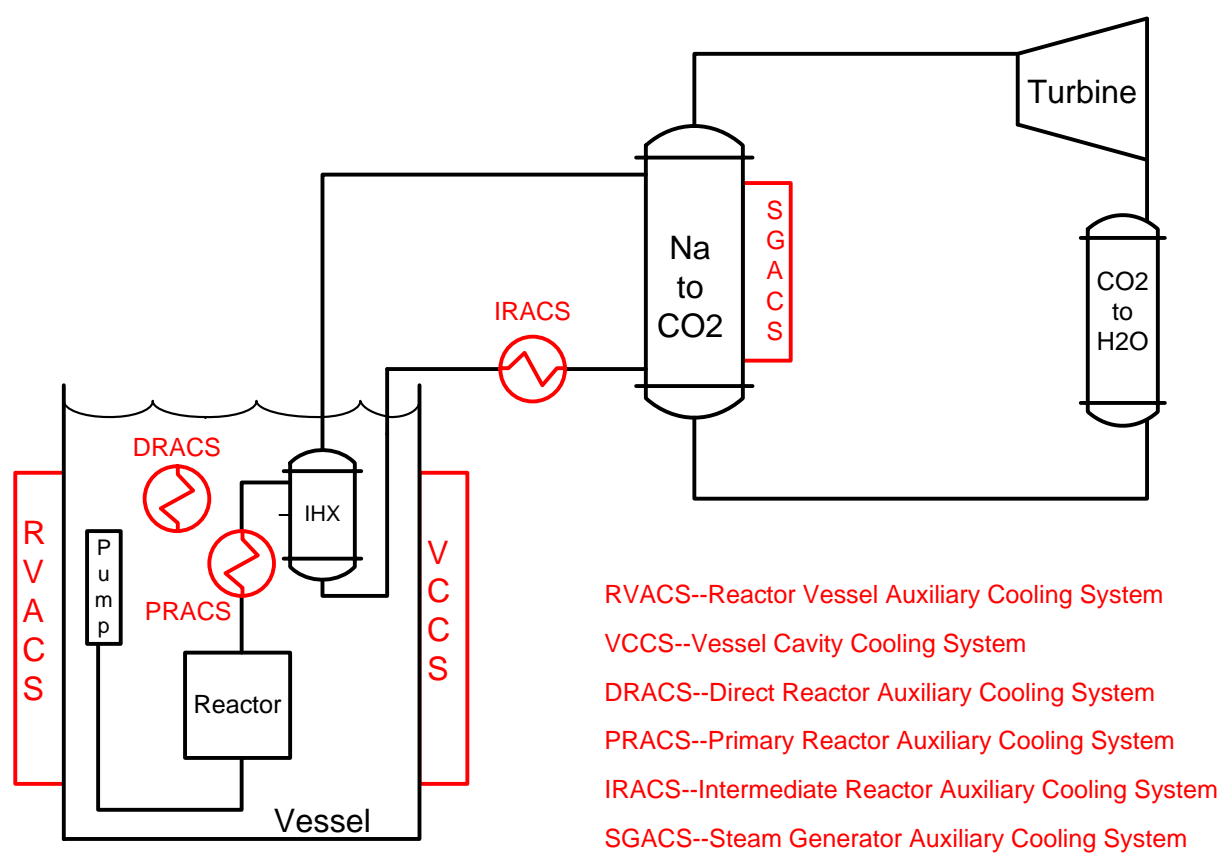

Figure 1. Options for decay heat removal from SFRs [34].

\subsubsection{Radionuclide Retention}

Perhaps the most critical FSF, radionuclide retention, is often evaluated using a barrier- or layers-ofdefense concept. Recently, the NRC approved [35] a functional containment concept [36] for advanced non-LWRs which values the importance of multiple barriers that, when taken together, effectively limit the physical release of radionuclides to the environment. This concept challenges the long-held view that a pressure retaining (i.e., leak-tight) containment should be required to satisfy the function of radionuclide retention during an accident. Many advanced reactor designs are proposing a functional containment approach over a traditional pressure-retaining containment design. Advanced technology such as seismic isolation may also improve barrier performance 
During an event, a plant's ability to limit heat generation and establish heat removal constrains the potential for radionuclide release to the next barrier by preventing degradation of the initial radionuclide retention barriers. Therefore, reliance on a subsequent radionuclide retention barrier such as a reactor building is reduced. For example, for one next-generation nuclear plant (NGNP) pebble-bed design, radionuclide retention was evaluated for many events, including those with the highest expected site boundary doses [37]. Radionuclide retention performance was evaluated for each barrier. Three principal barriers included:

- Fuel barrier

- Reactor coolant (helium pressure) boundary barrier

- Reactor building barrier

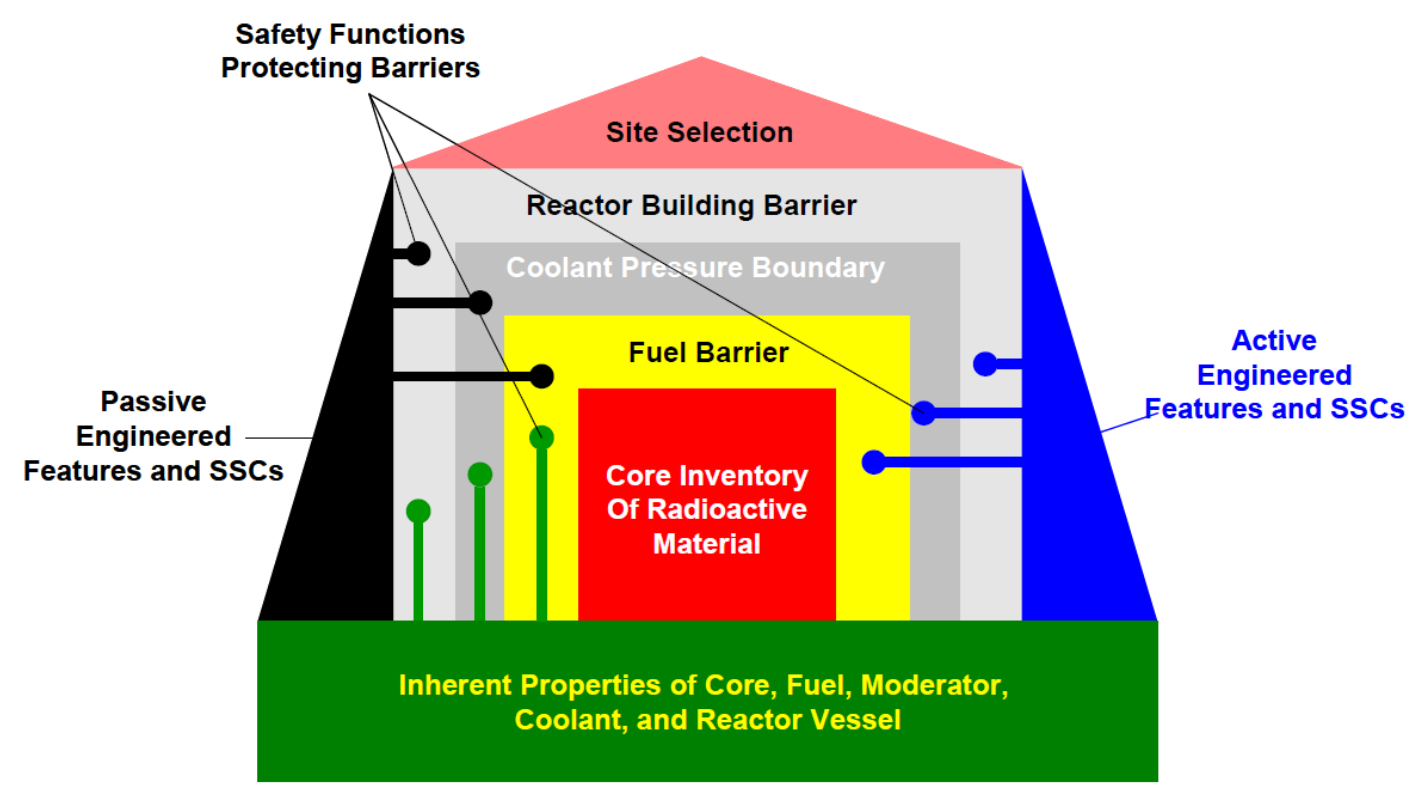

Figure 2. Plant capabilities for radionuclide retention and DID [38].

The combination of these three barriers to radionuclide retention led to a high estimation of the safety margin for the worst case NGNP events at the site boundary. Distance from the site boundary to the public can be considered as an additional barrier due to the reduction in potential dose as distance increases. However, with the greater radionuclide retention performance of the other barriers, the distance barrier may not need to be as effective to achieve an equivalent level of safety. Figure 2 [38] highlights a DID radionuclide retention approach applicable to many advanced reactors.

\subsection{BELOW-GRADE SITING AS AN ALTERNATIVE FOR DISTANCE}

Below-grade nuclear power reactor siting can mitigate the analyses required by $10 \mathrm{CFR} 50.54(\mathrm{hh})$ for loss of large plant areas due to fires and explosions. It can also act as an additional boundary layer against widespread fission product release. The concept of underground siting has been under consideration since the earliest days of nuclear power [39]. Pioneering nuclear physicists considered underground siting as an extension of DID to ease public anxiety regarding nuclear power.

My suggestion in regard to [the containment of nuclear material in case of an accident] is to place nuclear reactors 300 to 1000 feet underground... I think the public 


\section{misapprehension of risk can be corrected only by such a clear-cut measure as}

underground siting. - Edward Teller, 2001 Memoirs p. 565

While the potential for reduction in containment requirements was acknowledged, the primary rationale for underground siting was protection from attack. Underground siting was not selected for the first generation of commercial NPPs because the first underground plants would be somewhat more expensive to construct, more difficult to maintain, and there was greater availability of acceptable surface sites $[40,41]$. The economic penalty for underground construction was estimated to be between 10 and $60 \%$, with a progressively smaller penalty for later plants, based on a series of international studies conducted in the 1970s [42].

Underground locations can generally be subdivided into two options: (1) caverns bored into large rock formations, or (2) burial within shallower soil excavations, typically referred to as berm-contained facilities. All underground NPPs operated to date have been built in rock cavities. The largest underground nuclear plant was the Chooz A reactor, a 1,040 $\mathrm{MW}_{\text {th }}$ PWR that was operated from 1967 to 1991 near the border between France and Belgium [43].

Locating NPPs underground is not a panacea for avoiding all possibility of releasing radionuclides into the environment. NPP designs must be configured to take advantage of the nature of underground siting as a mitigation system for severe accidents. Simply emplacing a surface design within the earth may not substantially reduce public risks from severe reactor accidents [44]. Depending on reactor technology and accident mitigation features, an underground structure could pressurize with highly radioactive steam following a severe accident, and the pressurized radioactive steam could eventually be released to the environment. The degree to which advanced non-LWR plants would be vulnerable to a pressure build-up phenomenon depends on their designs. Systems that lack substantial water underground cannot build up significant quantities of steam. Systems that can effectively transfer decay heat into the surrounding earth by means such as heat pipes also minimize pressure build-up. Radionuclides could also be released from a below-grade reactor plant through the containment piping or cable penetrations without gross pressure rupture. Smoke from an underground fire following a severe accident could transport radionuclides to the surface, and radioactive noble fission gases could leak along piping or cabling penetrations. Furthermore, in wet locations following a severe accident, unconfined radionuclides could contaminate subsurface water sources. Overall, however, underground deployment of a properly designed, constructed, and maintained NPP can substantially reduce the potential impact of severe accidents. Essentially, belowgrade siting of an NPP has the potential to impact the NRC DID philosophy regarding the balance between (1) preventing the initiation of accidents, (2) limiting the progression of an accident, and (3) limiting the area subject to evacuation and time available in the event of accidental release of fission products. Therefore, below-grade siting could provide an applicant with a safety basis for reducing the current formula distance to population centers. Furthermore, the simple, clear-cut nature of underground siting may offer significant advantages in terms of public acceptability for future plant siting.

\subsection{THE NUREG-1537 SITING APPROACH}

NUREG-1537, Guidelines for Preparing and Reviewing Applications for the Licensing of Non-Power Reactors, provides performance-based guidance for the preparation and review of the siting aspects of a non-power reactor. The following Safety Analysis Report guidance [45] is provided for the applicant:

Population data presented should be based on the most recently available (last decade or later) census data. Information on population distributions should be in suitable form to use in dose analyses in Chapters 11 and 13 [waste management and accident analyses, respectively], in which potential doses down to a small percentage of 10 CFR Parts 20 or 100 may be applicable. 
On a map of suitable scale that identifies places of significant population grouping (such as cities and towns) within an 8-kilometer radius, concentric circles should be drawn, with the reactor at the center point, at distances of 1, 2, 4, 6, and 8 kilometers. The population in each area at the time of application and a projection of the population in five years and at the end of the license period should be given. The basis for population projections should be described. Information should be given about the direction and distance of the nearest permanent residence to the reactor and any reactor effluent exhaust points. Any part-time, transient, or seasonal occupation of buildings should be described, such as classrooms or dormitories on a university campus, giving best estimates of occupation times and numbers of occupants.

This guidance is similar to that provided for power reactors with respect to population data sources, as it accounts for transient population and population projections. However, the population analysis scale is reduced from 20 miles to 5 miles (8 kilometers), presumably based on the smaller core and source term associated with a non-power reactor. Also, no specific population density threshold is specified in the non-power reactor guidance.

The associated performance-based review guidance [46] to the staff advises the reviewer to "check the exclusion area distances against distances used in analyses presented in Chapters 11 and 13 of the SAR." The reviewer will find that:

- The demographic information is sufficient to allow accurate assessments of the potential radiological impact on the public resulting from the siting and operation of the proposed reactor.

- There is reasonable assurance that no geographic or demographic features render the site unsuitable for operation of the proposed reactor.

For example, the National Institute of Standards and Technology (NIST) test reactor (20 $\mathrm{MW}_{\text {th }}$ ) is located in Montgomery County, the most populous county in Maryland. The population within a 5-mile radius of the NIST campus is 223,000 based on 2000 Census data (2,839 ppsm). However, the entire emergency planning zone lies within the NIST campus. Access to the campus is controlled by a security force. In the most recent renewal safety evaluation report for the test reactor (June 2009), the staff found that the NIST site remains suitable for continued operation of the test reactor [47].

Therefore, NUREG-1537 holds that non-power reactor siting must be based on radiological dose analyses to the nearby population. However, because of the language in $10 \mathrm{CFR} 100.21(\mathrm{~h})$, power reactors are required to "be located away from densely populated centers and areas of low population density are, generally, preferred." To enforce this position, RG 4.7 advises that a power reactor should be located so that the population density does not exceed 500 persons per square mile averaged over any radial distance out to 20 miles (see Table A.2 for complete text). The NRC staff noted the following in a draft whitepaper on siting advanced reactors[1]:

Applying this population density guidance would be more limiting, in some cases, than the dose-based criteria in 10 CFR part 100. For example, under this guide, the population within a 1 mile radius of the reactor should be less than approximately 1,500 persons, the population within a 5 mile radius of the reactor should be less than approximately 40,000 persons, the population within a 10 mile radius should be less than approximately 150,000 persons, and the population within a 20 mile radius should be less than approximately 625,000 persons. 
Therefore, following the RG 4.7 population density guidance tends to force a power reactor to be sited well away from large cities as required by 10 CFR $100.21(\mathrm{~h})$. As a result, the population center distance requirement in 10 CFR 100.21(b) regarding a densely populated center with more than 25,000 residents would seem to be well met when applying the RG 4.7 population density guidance in the vicinity of a large city. This type of formula distance may have been appropriate because it provided additional DID to the public as the scale of LWRs became larger and larger over time. However, as more advanced reactors move toward smaller reactors with smaller source terms, a performance-based (dose) measure that is more in line with NUREG-1537 may be more appropriate.

\subsection{CHANGES IN THE PUBLIC VIEWS OF RISK SINCE THE DEVELOPMENT OF THE COMMISSIONS' POLICY}

Consideration of population distribution around a proposed NPP site is intended to ensure that there is no unreasonable risk to the public from the NPP. What is reasonable in terms of exposure to the environment and the public is the essence of societal risk. Risk is typically considered to be the product of accident frequency and consequence.

The US Atomic Energy Commission (AEC) begins to consider siting and population density in WASH-1308, Population Distribution around Nuclear Power Plant Sites [48]. The policy recommendation notes that technology was available for engineered safety features to make siting in densely populated areas feasible for meeting the individual dose guidelines stipulated in 10 CFR Part 100. However, the report states the following:

Reactors have been excluded from metropolitan areas to date for several reasons. It has been felt, as indicated in statements before the Joint Committee in 1965 and 1967, that advances in safety systems in terms of design, testing and reliability would be needed before siting in metropolitan areas would be allowed. There has been no reason to take the additional incremental risk, however small, of, incurring doses to a large metropolitan population as a result of any accident in the nuclear facility when other suitable sites, less densely populated, remain available. Also, the difficulty of instituting effective protective measures for the surrounding populace in the event of an accident increases with increased population density.

The AEC staff's position in this statement is that state-of-the-art safety systems are available, but the operating experience data are not abundant, and off-normal and accident experience is lacking. This is because early low-power LWRs tended to rely on the containment structure as the primary engineered safety feature. As LWRs grew larger, more sophisticated engineered safety features were introduced, but the accompanying operating experience was lacking. This led to policies that limit societal risk by promoting remote siting of NPPs (i.e., distance and population density). The WASH-1308 report states the following:

Reviews of population distributions have effectively discouraged large numbers of plants in areas of relative high population density by requiring engineered safety features to reduce computed consequences of design basis accidents to levels which are well within the dose guidelines of 10 CFR Part 100.

The report implies that additional or specialized engineered safety features (i.e., advanced technology) may be needed "to provide greater assurance of low risk."

Around the time period of the WASH-1308 study, Chauncey Starr, Dean of the School of Engineering and Applied Science at the University of California, Los Angeles, was evaluating the societal benefit of 
technology [49]. The paper notes that technological growth has been exponential in the $20^{\text {th }}$ century, doubling every 20 years. The paper states:

The conventional socioeconomic benefits-health, education, income-are presumably indicative of an improvement in the "quality of life." If we understood quantitatively the causal relationships between specific technological developments and societal values, both positive and negative, we might deliberately guide and regulate technological developments so as to achieve maximum social benefit at minimum social cost. Our society historically has arrived at acceptable balances of technological benefit and social cost empirically-by trial, error, and subsequent corrective steps.

Note that Starr's conclusion was drawn in 1969, right after the United States had landed astronauts on the moon. Technologies that impact societal views of safety associated with computer evolution, cell phones, the internet, and the advent of driverless cars were still to come. Starr goes on to divide societal perception of risk into voluntary and involuntary categories. People may voluntarily choose where to live and may consciously or subconsciously accept the risk associated with commuting or living near an external hazard. On the other hand, people may soon involuntarily risk an accident with a driverless car on the road. Based on the economic consequences of a reactor accident, Starr concludes the following:

... the public is willing to accept "voluntary" risks roughly 1000 times greater than
"involuntary" risks. In a sample application of these criteria to atomic power plant
safety, it appears that an engineering design objective determined by economic criteria
would result in a design-target risk level very much lower than the present socially
accepted risk for [non-atomic] electric power plants.

The WASH-1400 Reactor Safety Study was published a few years later [50]. This study attempted to relate known man-made societal risks such as dam failures, airplane crashes, fires, etc., and natural societal risks such as tornadoes, hurricanes, earthquakes, etc., to the collective risk of generating electricity from all the NPPs in the United States. WASH-1400 provided an initial use of PRA techniques to show that the probability of LWR core melt accidents was higher than previously expected when using deterministic methods; however, the consequences of such accidents were much lower than previously thought. Fifteen years later, NUREG-1150 [51] revisited severe accident risk at LWR NPPs using additional operating data for safety systems and components. This study found that the societal risk from operation of LWR NPPs was even lower than that found in the WASH-1400 study. Pressure-retaining containments were shown to be a major LWR engineered safety feature with regard to societal risk.

These studies tend to show that society embraces technology advances that provide a benefit that is worth the perceived risk. Advanced reactors that are demonstrated to be orders of magnitude safer than the current safe fleet of LWRs may be embraced at sites that are currently beyond consideration for current reactor technology. Based on previous studies of societal risk, such technological advances can include reactor designs that minimize the potential for traditional LWR accidents that lead to core melt, or advances may include reactor designs that eliminate containment pressurization events.

\subsection{CONCLUSIONS ON BASES FOR POSSIBLE CHANGE}

LWR operational data have accumulated over time, allowing for safety component and safety system reliability to be predicted more accurately with less uncertainty. In addition, better understanding of LWR fuel failure, coolant chemistry, aerosol behavior, accident progression, and failure timing have enabled better predictions of the timing and magnitude of fission product release from LWRs following severe accidents. The knowledge gained in modeling LWR fission product releases should provide a better basis for predicting fission product release associated with advanced reactors, although sufficient understanding 
of non-LWR fission product release and uncertainty must be demonstrated. Such improved understanding of fission product releases following an accident, coupled with appropriate emergency planning, could lead siting planners to support locating advanced reactors such as SMRs, non-LWRs, and micro-reactors closer to population centers without creating any increased risk to the public.

However, as the tsunami-induced accident at the Fukushima NPP has shown, one must also consider the possibility that land use may be denied following an accident. As a result, consideration should be given to the attributes of advanced reactors that fundamentally change the fission product release behavior following a reactor accident. This could include smaller source terms to minimize contamination potential, design attributes that eliminate or mitigate certain types of accidents, passive safety systems that initiate and operate without the need of operator action or other support systems, and reactor design characteristics such as low operating pressures that minimize the driving force to spread fission products beyond engineered barriers following an accident. In this case, enhanced tools to predict fission product release following an accident, coupled with improved accident mitigation attributes, should provide the opportunity to site advanced reactors closer to population centers while maintaining or improving current levels of DID. To avoid the limitations of arbitrary population density guidance, a performance-based approach based solely on radiological dose analyses to the nearby population such as that found in NUREG-1537 could be employed for advanced reactor siting guidance.

The public may still remain skeptical of improved reactor safety based solely on evolutionary or revolutionary reactor designs. Incorporation of a tangible technology such as below-grade siting may provide society with a technology paradigm shift that convincingly limits contamination resulting from an accident to the reactor site. Over time, the implementation of tangible technologies could alter the public's view of involuntarily living and working in the immediate proximity of an NPP versus the benefit derived from living adjacent to a clean power generation source with high-paying jobs and infrastructure benefits to the population center. Section 3 presents possible alternatives to current LWR-based siting requirements.

\section{POSSIBLE ALTERNATIVES TO CURRENT REQUIREMENTS}

As noted in NUREG-0478, Metropolitan Siting - A Historical Perspective, the history of reactor siting includes arguments of containment (emergency safeguards) versus isolation (distance) [3]:

[with regard to the Shippingport reactor] AEC Chairman W. F. Libby articulated that the principle of defense-in-depth was to be applied to the design of new reactors and expressed the policy that "power reactors... will rely more upon the philosophy of containment than isolation as a means of protecting the public against the consequence of an improbable accident, but in each case there will be a reasonable distance between the reactor and major centers of population."

This approach eventually led to an application for a $1000 \mathrm{MW}_{\mathrm{e}}$ PWR with a double containment in Queens, New York, with a population of 5 million people within 5 miles. Adverse public reaction scuttled this project, and over time, siting requirements in 10 CFR 100 and guidance in RG 4.7 provided more specific population density and distance guidance for LWR reactor sites. However, based on the discussion presented earlier in Section 2, there appear to be ample bases for the NRC staff to consider further clarification of the current population siting guidance for advanced reactors (SMRs, non-LWRs, and micro-reactors). 


\subsection{EQUIVALENCY TO CURRENT REQUIREMENTS}

An application for a construction permit under 10 CFR 50.34 or an application for a combined license under 10 CFR 52.79 must show that dose limits to individuals on the EAB and to individuals on the outer boundary of the low population zone (LPZ) are not exceeded (see Table A.1 for definitions and specific values). An application for an advanced reactor will be required to show that it meets some equivalency to the cumulative societal risk imposed by these limits.

\subsubsection{Societal Safety Measures}

Time, distance, and shielding constitute the societal safety triad for radionuclides. Worst-case LWR DBAs have historically been used to determine the radionuclide release inside containment. Containment leakage estimates in the absence of other effective engineered safety features have been used to predict the source term and, therefore, the effective risk to society from proximity to an operating LWR. Over time, the AEC and its successor, the NRC, have sought design-independent population siting guidance that could be consistently applied to each LWR application to demonstrate adequate health and safety of the public. NUREG-0625, Report of the Siting Policy Task Force [52], made several siting policy recommendations for this purpose. Of the time, distance, and shielding protective elements, distance is the element that can consistently be structured for public safety through regulations and guidance. Time and shielding are dependent on individual designs. A distance factor requires consideration of the closest population centers and ultimately the surrounding population density. Therefore, one stated policy goal in NUREG-0625 is:

to take into consideration in siting the risk associated with accidents beyond the design basis by establishing population density and distribution criteria.

Prior to NUREG-0625, the AEC in WASH-1308 [48] proposed specific regulatory guidance for population density at 5, 10, 20, and 40 miles that exceeded 380-400 ppsm. Sites having a cumulative population projected from the date of application for a construction permit greater than 30,000 within 5 miles (382 ppsm), 120,000 within 10 miles (382 ppsm), 500,000 within 20 miles (398 ppsm), or 2,000,000 within 40 miles (398 ppsm) should:

(a) Present an analysis of alternative sites, including a showing that the proposed site offers significant advantages from the standpoint of environmental, economic or other factors.

(b) Provide state-of-the-art engineered safety features to assure that the conservatively calculated consequences of postulated design basis accidents are significantly below the dose guidelines of 10 CFR Part 100.

(c) Have a minimum exclusion distance of at least 0.4 mile and a low population zone of at least two miles.

The WASH-1308 study concludes that (1) remote locations are best but not mandatory, (2) there is a population density target that sites should try to stay below, and (3) advanced technology may provide adequate limits to societal risk such that the surrounding population is not exposed to any undue risk. These conclusions actually set the stage for renewed consideration of the cumulative societal risk associated with the attributes of advanced reactors. However, siting guidance has consistently focused on remote siting.

As demonstrated by the evolution of the proposed population values from WASH-1308 to current guidance found in RG 4.7, General Site Suitability Criteria for Nuclear Power Stations [2], the 
appropriate societal safety measure provided by design-independent fixed population density/distance formulas that are independent of LWR design is reasonably consistent. An accepted societal risk limit for population center distance, implied by RG 4.7, is shown in Figure 3 [53]. The RG 4.7 guidance implies that the 10 CFR 100 dose limits will be satisfied if the guidance limitations of 500 ppsm on population density in the plant vicinity are met. The draft NRC siting considerations white paper [1] notes that "applying this population density guidance would be more limiting, in some cases, than the dose-based criteria in 10 CFR part 100."

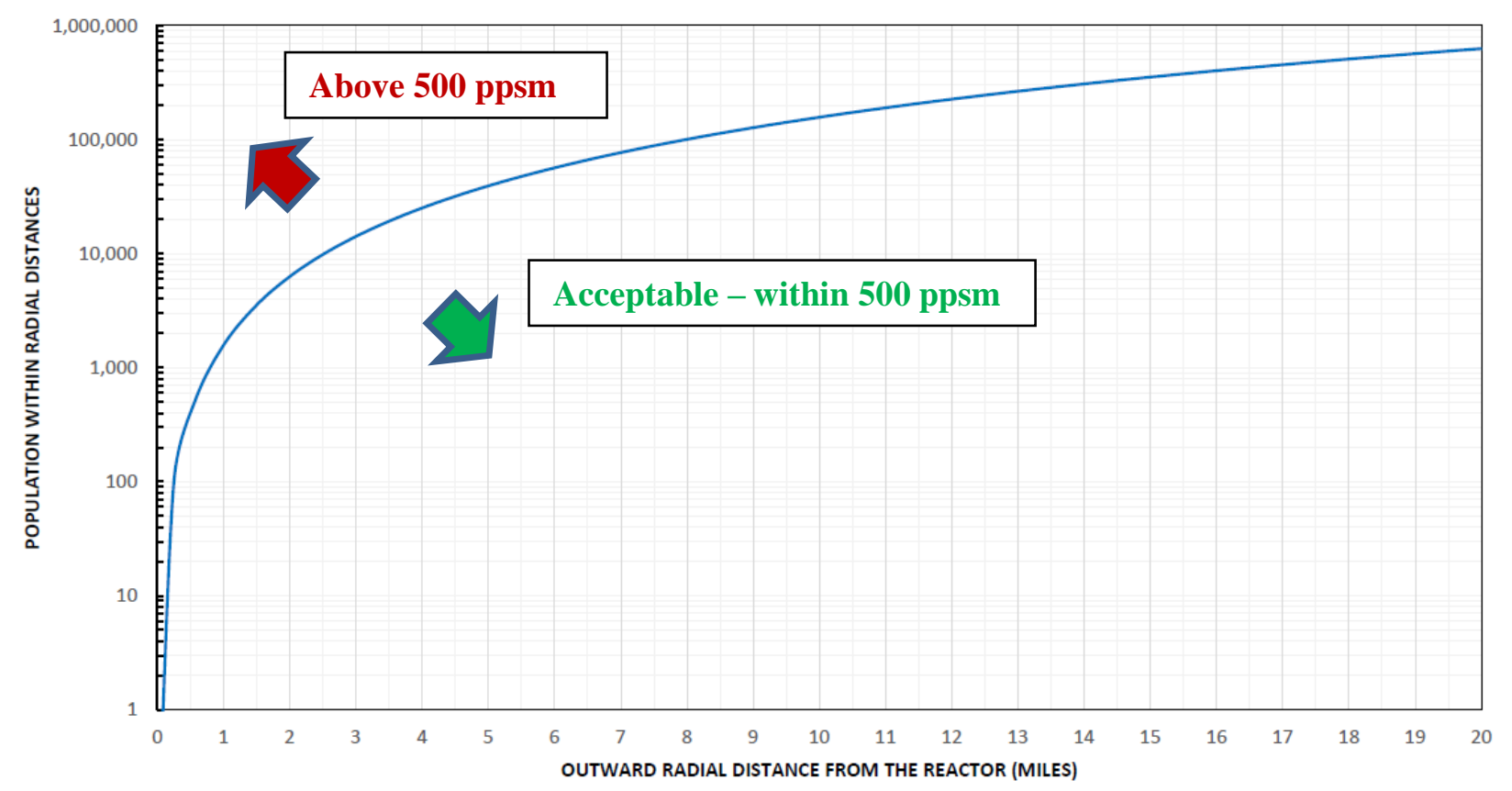

Figure 3. Population density of 500 ppsm per RG $4.7[2,53]$.

The RG 4.7 guidance approach assigns all the responsibility for limiting societal risk onto fixed population density/distance formulas to provide adequate health and safety of the public. Essentially, this approach provides a standoff distance from an LWR to a population center of a given size. For example, an LWR should not be sited any closer than 4 miles from a population center of 25,000 residents, and adherence to 10 CFR 100 would dictate that the outer boundary of the LPZ be set at 3 miles. A larger population center of 100,000 people should be no closer than 8 miles from an LWR, and that same LWR should be located no closer than 20 miles from a population center of approximately 625,000 people. The benefit of such an approach is that it simplifies the discussion of initial site selection for large LWRs while providing an acceptable limit on societal risk. However, the current RG 4.7 guidance may hamper the initial siting of advanced reactors that could otherwise benefit from improved attributes and existing infrastructure, such as municipal power plant sites close to population centers.

NUREG-0396, Planning Basis for the Development of State and Local Government Radiological Emergency Response Plans in Support of Light Water Nuclear Power Plants [54], succinctly states the difficulty of revising current reactor siting guidance to take advantage of advanced reactor attributes:

Societal risk is not generally thought of in terms of probabilities and consequences, rather it is an intuitive feeling of the threat posed to the public. Reactors are unique in this regard: radiation tends to be perceived as more dangerous than other hazards because the nature of radiation effects are less commonly understood, and the public generally associates radiation effects with the fear of nuclear weapons effects. 
Therefore, a quantitative analysis of acceptable societal risk based on the current accepted risk for large LWRs is necessary to provide a bound for subsequent advanced reactor risk. The challenge for advanced reactors in terms of societal safety measures is to alter the distance and population density discussion based on the attributes of these designs.

\subsubsection{Science-Based Safety Measures}

Science-based safety measures can focus on calculated dose to the public, ratios of acceptable societal risk based on advanced reactor attributes related to LWR attributes, and limiting the dose-based reactor site criteria to that set forth in $10 \mathrm{CFR} 100 .{ }^{2} \mathrm{RG} 4.7$ provides guidance to site a reactor such that, at the time of initial plant approval, and within about 5 years thereafter, the population density averaged over any radial distance out to 20 miles does not exceed $500 \mathrm{ppsm}$. Implicit in this guidance is the presumption that the 20-mile radius assumes a potential dose greater than zero but no more than the maximum allowable under 10 CFR 100 requirements for all persons within the LPZ, assuming the emergency plan is executed.

Technical Information Document 14844 [10] provided a conservative basis for fission product release to containment. Subsequent NUREG and SOARCA information on LWR fission product release $[4,5,6,11,15]$ is assumed to have formed the initial basis for the RG 4.7 siting guidance based on a large source term in which $65 \%$ of the core inventory of ${ }^{137} \mathrm{Cs}$ and $45 \%$ of the ${ }^{131} \mathrm{I}$ would be released to the atmosphere following a severe, large LWR accident. Over time, these estimates have proven to be very conservative. However, the RG 4.7 guidance has remained consistently conservative because the concept of acceptable societal risk is often vague in the eyes of the public. Many advanced reactors are expected to have one or more attributes such as smaller cores, smaller source terms, passive safety features, enhanced release barriers, and reduced operating pressures that will provide for smaller releases in the event of an accident. Analyses of many advanced reactor designs and attributes are expected to show that reactor accidents will (1) result in a significantly reduced source term and/or (2) limit any radioactive material fallout to within the site boundary or be limited to within a short distance of the EAB.

Estimates of the dose to the public from an advanced reactor technology DBA requires analyses that are generally based on proprietary information. This type of information is unavailable for this discussion, and multiple technology calculations are beyond the scope of this paper. However, if the dose to the public from an LWR DBA is assumed to be within limits specified in 10 CFR 100 using the conservative guidance from RG 4.7, then some aggregate societal risk ratios can be considered for advanced reactors in comparison to large LWRs. This methodology will not resolve the difference in dose between individuals on the EAB and individuals just inside the 20 -mile radius.

The area of a circle is given by $A=\pi r^{2}$, where $A$ is the area and $r$ is the radius of the circle. The guidance from RG 4.7 is to analyze sites limited to 500 ppsm out to a radius of 20 miles. The area swept out by a 20 -mile circle is $1,256.6$ square miles. Multiplying the population density limitation of 500 ppsm for this area, an LWR should be limited to no closer than 20 miles to a population center of 628,000 people. An average dose per person could be applied to this 20-mile population to establish a societal risk value in person-rem as desired. However, for the purpose of this comparison, a ratio of aggregate acceptable societal dose will suffice for a generic population density evaluation. This relation can be seen in the following formula:

$$
\mathrm{SR}=\pi \mathrm{r}^{2} \times \mathrm{D} \times \mathrm{PPSM}
$$

\footnotetext{
${ }^{2} 10$ CFR 100.21 references 10 CFR 50.34 for actual dose limits.
} 
where

$\mathrm{SR}=$ accepted societal risk in terms of large LWRs, $\mathrm{r}=$ assumed radius of consideration,

$\mathrm{D}=$ assumed dose to the public in the area of consideration, and

PPSM $=$ assumed population density in the area of consideration.

If an argument can be made that advanced reactors will release a fraction of the source term following a DBA compared to the conservative source term associated with an LWR DBA and the RG 4.7 guidance, then some significant adjustments can be considered for the distance and population density guidance for these reactors. A reasonable approximation for comparison is that at a fixed distance under identical meteorology conditions, radiation dose to the public is linear with the source term. This means that if the radiological mixture is the same, then a reduction in source term that produces half the radiological isotopes would produce half the dose at a point in space. The dose relationship can be demonstrated graphically using the dose intensity equation:

$$
\mathrm{D}_{2}=\mathrm{D}_{1} \times\left(\mathrm{r}_{1} / \mathrm{r}_{2}\right)^{2}
$$

where

$\mathrm{r}=$ assumed radius of consideration at point 1 and point 2 , and

$\mathrm{D}=$ assumed dose to the public in the area of consideration at point 1 and point 2 .

Figure 4 shows that the initial source term / radiation dose proportionality is maintained through the distance of interest.

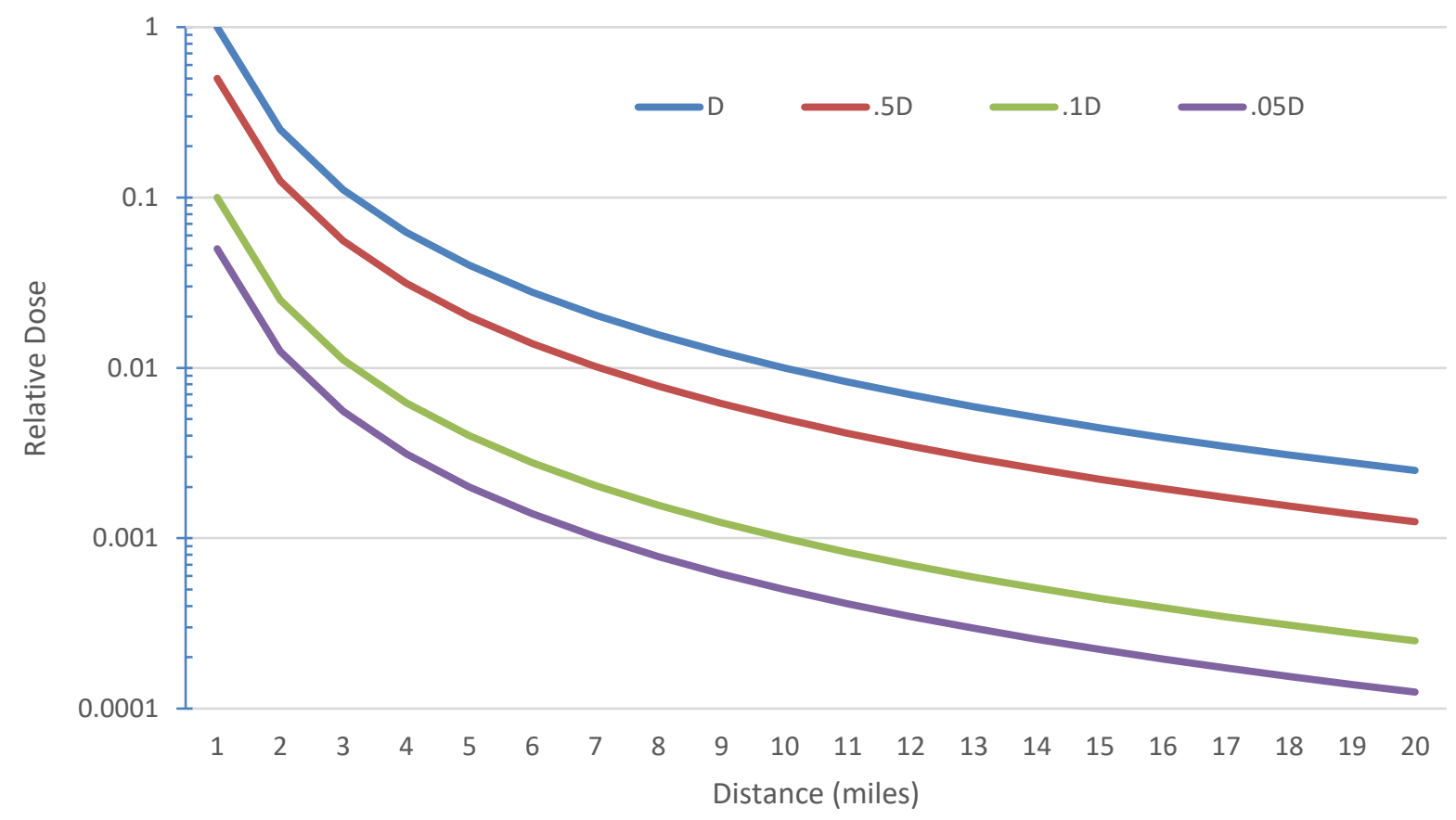

Figure 4. Comparison of dose intensity for dose $\mathrm{D}, .5 \mathrm{D}, .1 \mathrm{D}$, and $.05 \mathrm{D}$ to 20 miles. 
Using this assumption for a similar accident and fission product release fraction and the societal risk formula above, the cumulative accident dose to a population limited to a density of $500 \mathrm{ppsm}$ out to a radius of 20 miles from an LWR that meets 10 CFR 100 limits can be ratioed and would be equivalent, with some uncertainty, to the cumulative advanced reactor accident dose received by an equivalent number of people over a smaller area. The best ratio should be based on actual source term values (fission product release to atmosphere) and ultimately, advanced reactor vendors will be required to perform analyses to prove the reduction in source term. However, lacking actual source term data, a sufficient proxy for source term would be core thermal power. A reasonable large LWR standard for the societal risk ratio would be a 3,000 $\mathrm{MW}_{\text {th }}\left(1,000 \mathrm{MW}_{\mathrm{e}}\right)$ machine.

Using the formula above and assuming both a constant population density and the same acceptable dose limit, for the case of a $300 \mathrm{MW}_{\text {th }}$ advanced reactor with a tenth of the source term of the standard large LWR, a ratio of equivalent societal risks can lead to an impacted area due to the proximity to an advanced reactor that is a tenth the size of the large LWR equivalent. Such an area relative to a circle with a 20-mile radius would be 125.7 square miles and would be equivalent to a circle with a radius of just 6.3 miles. The original affected population $(628,000$ people) can now be assumed to be contained within 6.3 miles of the advanced reactor without an increase in aggregate acceptable societal risk to the cumulative population, as outlined in RG 4.7. This results in a population density of 5,000 ppsm to be considered for siting a hypothetical advanced reactor with a tenth the source term of a large LWR. However, an uncertainty margin for the assumption of linear dose with source term and the location of the population relative to a radiation plume should be applied for added conservatism. Strictly speaking, there is no need for an uncertainty margin because the results are taken from a mathematical ratio to an acceptable societal risk in the formula above. However, if the source term from different advanced reactors consists of dissimilar radiological mixtures or if accident progressions are different, then some consideration to the dose linearity assumption is warranted. If the desired uncertainty margin is $25 \%$, then a circle with an area of 157.1 square miles $(1.25 \times 125.7)$ and a radius of 7.1 miles can be considered as bounding the comparable risk to the public. Now, the original affected population $(628,000$ people) can be assumed to be contained within 7.1 miles of the advanced reactor without an increase in acceptable societal risk to the cumulative population as outlined in RG 4.7. This results in a reduced limiting population density of 4,000 ppsm to be considered for siting a hypothetical advanced reactor with a tenth of the source term of a large LWR plus additional uncertainty margin. Conservatism is added by reducing the calculated allowable ppsm value for the advanced reactor siting. A revised guidance curve such as that shown in Figure 3 can be prepared for this updated population density out to 20 miles.

Sensitivity calculations can be made for source term reductions on either side of this revised $10 \%$ source term curve at half the original LWR source term and at $1 / 20$ the original source term. Results of the calculations are shown in Table 1, including calculations out to 20 miles for each density. 
Table 1. Population density calculation results

\begin{tabular}{|c|c|c|c|c|c|}
\hline Source term & & $x$ & $0.5 \times$ & $0.1 \times$ & $0.05 x$ \\
\hline Radius (miles) & & 20 & 14.1 & 6.3 & 4.5 \\
\hline $\begin{array}{l}25 \% \text { margin } \\
\text { (miles) }\end{array}$ & & & 15.8 & 7.1 & 5 \\
\hline \multirow[b]{2}{*}{ Miles } & Pop. density: & 500 & 800 & 4,000 & 8,000 \\
\hline & Area & \multicolumn{4}{|l|}{ Population } \\
\hline 0.1 & 0.03 & 16 & 25 & 126 & 251 \\
\hline 1 & 3.1 & 1,571 & 2,513 & 12,566 & 25,133 \\
\hline 2 & 12.6 & 6,283 & 10,053 & 50,265 & 100,531 \\
\hline 3 & 28.3 & 14,137 & 22,619 & 113,097 & 226,195 \\
\hline 4 & 50.3 & 25,133 & 40,212 & 201,062 & 402,124 \\
\hline 5 & 78.5 & 39,270 & 62,832 & 314,159 & 628,319 \\
\hline 6 & 113.1 & 56,549 & 90,478 & 452,389 & 904,779 \\
\hline 7 & 153.9 & 76,969 & 123,150 & 615,752 & $1,231,504$ \\
\hline 8 & 201.1 & 100,531 & 160,850 & 804,248 & $1,608,495$ \\
\hline 9 & 254.5 & 127,235 & 203,575 & $1,017,876$ & $2,035,752$ \\
\hline 10 & 314.2 & 157,080 & 251,327 & $1,256,637$ & $2,513,274$ \\
\hline 11 & 380.1 & 190,066 & 304,106 & $1,520,531$ & $3,041,062$ \\
\hline 12 & 452.4 & 226,195 & 361,911 & $1,809,557$ & $3,619,115$ \\
\hline 13 & 530.9 & 265,465 & 424,743 & $2,123,717$ & $4,247,433$ \\
\hline 14 & 615.7 & 307,876 & 492,602 & $2,463,009$ & $4,926,017$ \\
\hline 15 & 706.9 & 353,429 & 565,487 & $2,827,433$ & $5,654,867$ \\
\hline 16 & 804.2 & 402,124 & 643,398 & $3,216,991$ & $6,433,982$ \\
\hline 17 & 907.9 & 453,960 & 726,336 & $3,631,681$ & $7,263,362$ \\
\hline 18 & $1,017.9$ & 508,938 & 814,301 & $4,071,504$ & $8,143,008$ \\
\hline 19 & $1,134.1$ & 567,057 & 907,292 & $4,536,460$ & $9,072,920$ \\
\hline 20 & $1,256.6$ & 628,319 & $1,005,310$ & $5,026,548$ & $10,053,096$ \\
\hline
\end{tabular}

A comparison of equivalent societal risk for the various source term ratios, including an additional $25 \%$ margin, is shown in Figure 5, with the 500 ppsm baseline shown as the bottom curve. Significant siting flexibility is provided for advanced reactors with a reduced source term. For example, an advanced reactor with a tenth the source term of a large LWR could theoretically be located within 10 miles of a population center of 1 million people without an increase in the current accepted societal risk. 


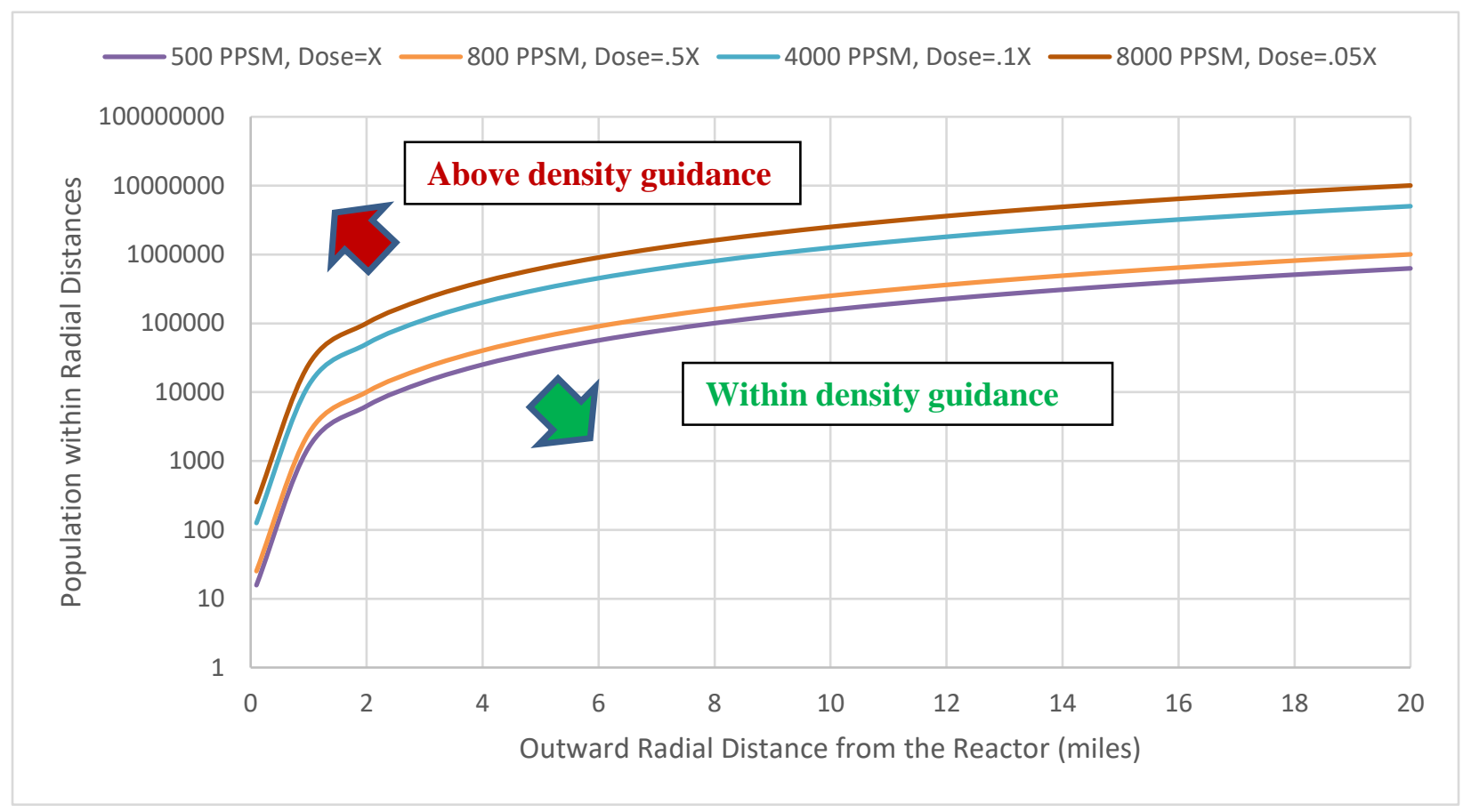

Figure 5. Population density comparison.

\subsubsection{Consequence Assessment}

The siting requirements in 10 CFR 100 in conjunction with 10 CFR 50.34 and 10 CFR 52.79 direct that the population center distance for a population of 25,000 residents be at least $1 \frac{1}{3}$ times the distance from the reactor to the outer boundary of the LPZ. The point at which each of the PPSM curves intersects a population of 25,000 residents can be roughly determined by inspection of Figure 5, or it can be accomplished more precisely by multiplying the PPSM limit times the area of the circle of interest and solving for the radius:

$$
\begin{gathered}
25,000 \text { residents }=\text { PPSM } \times \pi r^{2} \\
r=\sqrt{(25,000} /(\mathrm{PPSM} \times \pi)),
\end{gathered}
$$

where

$\mathrm{r}=$ assumed radius of consideration, and

PPSM = population density limit in the area of consideration.

The solved radius is equivalent to the population center distance for the purposes of the $10 \mathrm{CFR} 100$ requirement. By definition, the $\mathrm{LPZ}$ is $3 / 4$ of this distance. Using this approach, Table 2 specifies the distance to a population center of 25,000 residents and the associated LPZ for the baseline of $500 \mathrm{ppsm}$ and the alternatives shown in Figure 5. As shown in the table, at the baseline density (500 ppsm), the LPZ should be at least 3 miles. However, increasing the population density to 4,000 ppsm by siting a 300 $\mathrm{MW}_{\text {th }}$ advanced reactor reduces the LPZ to 1.1 miles; which is essentially $1 / 3$ the distance of that using a population density of $500 \mathrm{ppsm}$. An even smaller advanced reactor-such as a $150 \mathrm{MW}_{\text {th }}$ advanced reactor with $1 / 20$ the standard LWR source term has a projected LPZ of 0.7 miles. At this reduced distance, the LPZ is likely approaching a reasonable EAB size for a utility that desires to operate an advanced reactor. Based on these small LPZ distances commensurate with the dose reduction factors afforded by 
advanced reactors, low-population industrialized areas within a surrounding high-density population center could conceivably support advanced reactor siting within the requirements of 10 CFR 100.

Table 2. 10 CFR 100 calculations based on PPSM

\begin{tabular}{|c|c|c|}
\hline \multicolumn{3}{|c|}{25,000 resident population center } \\
\hline PPSM & Distance (miles) & LPZ (miles) \\
\hline 500 & 4.0 & 3.0 \\
\hline 800 & 3.2 & 2.4 \\
\hline 4,000 & 1.4 & 1.1 \\
\hline 8,000 & 1.0 & 0.7 \\
\hline
\end{tabular}

\subsection{ENGINEERED SAFETY FEATURE CONSIDERATIONS}

The historical distance-related measures of societal risk are based on a maximum hypothetical accident for an LWR, which is recognized to be a large-break LOCA with core damage, and a calculation of a standoff distance that is evaluated by expert judgement to provide adequate decay and dispersion of radionuclides [3]. As the bounds for what constituted an undue risk to society were being developed, confirmation of the reliability and efficacy of LWR engineered safety features toward risk mitigation was not mature. The resulting guidance developed in RG 4.7 for a population density evaluation ( $500 \mathrm{ppsm})$ out to 20 miles to bound any societal risk has remained unchanged. In fact, the impact of using advanced technology engineered safety features to mitigate accidents is not factored into the curve in Figure 3.

Today, the reliability and efficacy of LWR engineered safety systems are better understood, documented, and modeled. The understanding of engineered safety features and enhanced modeling techniques can be applied to advanced reactors using passive safety systems and enhanced barriers (including below-grade siting) to reduce the risk of radionuclide release. Modern analyses indicate that advanced reactor engineered safety systems substantially reduce both the probability and magnitude of a radionuclide release to the public. This point should be used as an argument to leverage engineered safety features for complementing distance in a DID equivalency analysis related to reactor siting and undue societal risk. The cumulative advanced reactor accident dose to the public, mitigated by engineered safety features, can be compared to the cumulative dose associated with an LWR large-break LOCA that was mitigated only by containment and that provided the basis for current population-related siting guidance.

\subsubsection{Consequence Assessment}

Accounting for the engineered safety features can directly complement the proposal for associating a reduced source term with advanced reactors based on reactor thermal output. In fact, engineered safety features that complement functional containment integrity may negate the need to add margin for source term uncertainty (Section 3.1.2) while employing that methodology for revised siting guidance. This study examines a reduction in a hypothetical $300 \mathrm{MW}_{\text {th }}$ advanced reactor source term assumed by the siting guidance by an order of magnitude relative to the conservative values used for large LWRs (0.1 ratio). The subsequent siting approach recommended is to revise the population density for advanced reactors to a value that is risk-neutral at one tenth the source term and continue to evaluate the population density at the revised value out to 20 miles from the center of the reactor site.

An alternative that maintains the current population density evaluation guidance in RG 4.7 is to reduce the impacted area in the manner described in Section 3.1.2 based on the effectiveness of the engineered safety features. However, under this alternative, the population density evaluated is not increased. Instead, 
the radius for the population density evaluation at $500 \mathrm{ppsm}$ could be reduced. Such a reduction can remain very conservative if the density evaluation remains at 500 ppsm but is limited to some new radius provided by the source term / dose ratio analysis. This would provide the opportunity for siting advanced reactors closer to population centers by limiting the area that must be evaluated for population density. This is also conservative in that the immediate population density remains limited to the current guidance limit. However, this would require that a performance criterion be established for engineering safety features that would require validation similar to containment leak rate testing on large LWRs.

Perhaps only a 2-, 5-, or 10-mile population density evaluation at 500 ppsm may be necessary. This would open areas on the fringe of a heavily populated city for reactor siting as depicted in Figure 6 . Using Kansas City as a proxy for siting in Figure 6, areas that exceed a population density of 500 ppsm are depicted for calculations of varying radii. At 2 miles, areas that exceed $500 \mathrm{ppsm}$ are shown in purple. The same calculation at 5 miles is represented by the purple and green colored areas on the map. The same calculation at 10 miles is represented by the purple, green, and red colored areas on the map. Finally, the same calculation at 20 miles is represented by the purple, green, red, and teal colored areas on the map. Therefore, this map provides a sense of urban sprawl from the densest population shown in purple out to less densely populated areas that exceed 500 ppsm because of the portion of the more densely populated areas included in the expanding area calculation. If credit is given to engineered safety features such that the radius of the population density calculation can be limited, then the colored areas on the fringe of the city will start to drop off and become available for advanced reactor siting. Industrialized areas within the city core also become available for siting consideration. Any preexisting electrical infrastructure in these fringe areas would then also become available for siting consideration. A few sample coal plant sites are depicted as yellow dots in Figure 6.

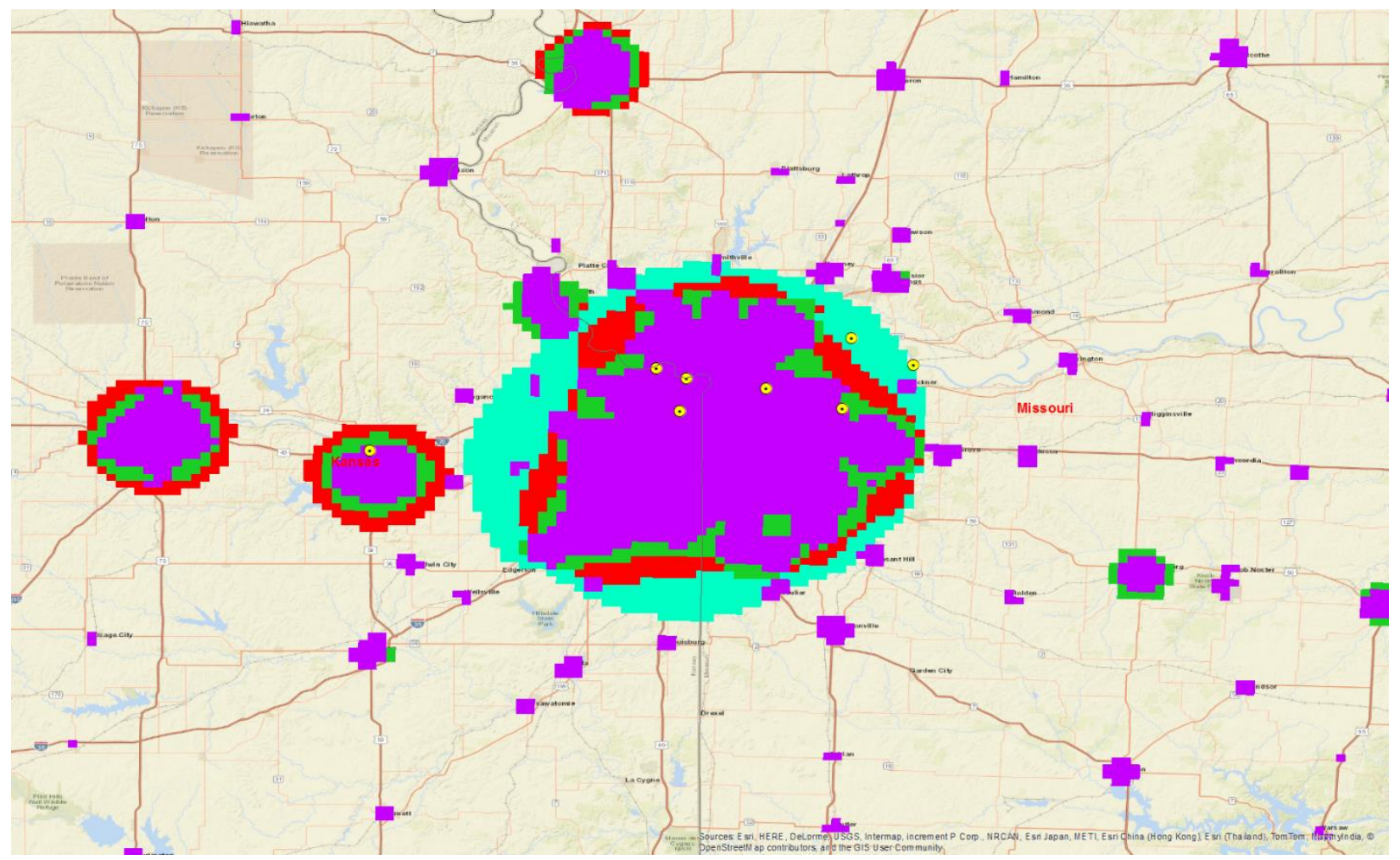

Figure 6. Sample population density calculations for 2030 around Kansas City. 


\subsection{SPECIFIC TECHNOLOGY CONSIDERATIONS}

The generic approaches discussed in Section 3.1 and Section 3.2 are intended to generate discussion on approaches to reactor siting that are independent of the reactor design while reflecting the combined attributes of most advanced reactors currently under consideration. This is consistent with the early siting goals considered in NUREG-0625 [52], including the goal "to strengthen siting as a factor in defense-indepth by establishing requirements for site approval that are independent of plant design consideration."

Each advanced reactor will have one or more unique features that will provide for smaller releases in the event of an accident. As noted in the previous sections, the historical distance-related measures of societal risk are based on a large LWR LOCA and a calculation of a standoff distance that is evaluated by expert judgement to provide adequate decay and dispersion of radionuclides [52]. However, many advanced reactor technologies have eliminated the large-break LOCA event and the associated containment pressure surge through design and/or the application of non-LWR technologies. Many advanced designs operate at or near atmospheric pressure, which eliminates a significant driver in releasing radionuclides following an accident. Some designs have a very large negative temperature coefficient of reactivity that significantly limits power excursions and any subsequent fuel damage. Most advanced designs provide for passive cooling, which can reduce or eliminate the need for operator action. Therefore, advanced reactor vendors are likely to define more benign maximum hypothetical accidents due to a combination of attributes. In addition, advanced reactors will likely employ a set of barriers and engineered safety features to greatly mitigate the source term associated with an accident. However, it is unlikely that all advanced reactors will be able to model similar reductions in source term.

If advanced reactors are lumped together generically, then any relaxation in siting considerations compared to the guidance provided for large LWRs will have to be conservatively bounded to allow for the characteristics of each technology and design. Current modeling and simulation techniques make it possible to provide reasonable calculations, including uncertainty, of the dose to members of the public based on DBAs and beyond DBAs. Therefore, it may be advantageous for vendors to forego technologyneutral siting guidance and subsequently build a siting case based on the reactor-specific siting analyses they must provide to the NRC. The NRC siting guidance could be revised to inform vendors that such an option is always available. The siting guidance could be updated to provide parameters for defining and analyzing worst-case accidents and the subsequent impact on siting related to the health and safety of the surrounding population, interfaces with other industrial processes, and the protection of the environment.

\subsubsection{Informal Consequence Assessment}

Depending on the specific advanced reactor design, size of the core, safety systems, and land controlled by the operator, analyses may show that there are negligible onsite and offsite consequences following a reactor accident. Obviously, such analyses are design specific, but they could be used to show on a caseby-case basis that advanced reactors can be sited very close to population centers with no undue risk to society and no sacrifice of current DID principles in play with current siting guidance. A reactor analysis specific option may be appropriate to add to RG 4.7 for advanced reactors, although this option will result in a more labor intensive process for applicants and reviewers.

\subsection{OTHER ALTERNATIVES}

As noted previously, time, distance, shielding, and source term are the key parameters in any discussion of public safety with respect to reactor siting. Including some consideration of meteorological effects, these parameters essentially determine the public dose associated with a worst-case accident. Since individual advanced reactor attributes affect time, shielding, and source term, one is left to manipulate the remaining distance factors (distance, population, population density) to preserve equivalent health and 
safety of the public and the environment when considering siting guidance. Risk-informed siting could play a role in establishing distance factors with regard to natural phenomena such as hurricanes, tornados, floods, earthquakes, etc.

A generic siting guidance approach that is independent of the advanced reactor design has the benefit of consistency and clarity for a variety of applicants. However, with conservative margins applied to account for uncertainty, a generic approach may still be too economically restrictive for some applicants. On the other hand, design-by-design reviews can lead the NRC back down the path of the early days of commercial NPPs in which applicants constantly pushed the siting envelope until a set of independent siting guidance had to be developed and applied.

\subsection{REGULATORY GUIDE 4.7 IMPLICATIONS}

The Staff Regulatory Guidance on population is provided in Section C.5 of RG 4.7. The key population considerations are included in the following two paragraphs [2]:

Locating reactors away from densely populated centers is part of the NRC's defense-indepth philosophy and facilitates emergency planning and preparedness, as well as reduces potential doses and property damage in the event of a severe accident.

Numerical values in this guide are generally consistent with past NRC practice and reflect consideration of severe accidents, as well as the demographic and geographic conditions characteristic of the United States.

A reactor should be located so that, at the time of initial plant approval within about 5 years thereafter, the population density, including weighted transient population, averaged over any radial distance out to $20 \mathrm{mi}$ (cumulative population at a distance divided by the circular area at that distance), does not exceed 500 persons per square mile. A reactor should not be located at a site where the population density is well in excess of this value.

These two paragraphs should be revised to exclusively reference large LWRs. For example, the first sentence could be revised to state, "Locating large light-water reactors away from densely populated areas..." Corollary paragraphs could then be developed for advanced reactors, including SMRs, nonLWRs, and micro-reactors. The new paragraphs could note the risk-reduction attributes of advanced reactors and the reduced source term. Depending on the alternative approach selected and an accepted source term reduction, the specific values can be updated.

\subsection{CONCLUSIONS ON POSSIBLE ALTERNATIVES TO CURRENT REQUIREMENTS}

Supporting documentation for any revision to the siting guidance for advanced reactors must clearly show that the public in the vicinity of a locally sited smaller reactor will not be subjected to any more risk than the public in the vicinity of a more remotely sited large reactor. This can be accomplished by building additional margin into ratio calculations or by maintaining some aspects of the conservatism of the current guidance.

The population considerations for siting advanced reactors need to be revised based on their attributes. The key for a reactor design independent approach is to make appropriate assumptions to bound the collective source term for advanced reactors. The original premise for siting large LWRs is based on a specific accident with very conservative assumptions regarding the large LWR accident source term and only considers the source term mitigation afforded by containment. Many advanced reactors are expected to have one or more attributes to provide for smaller releases in the event of an accident, such as accident 
elimination by design, smaller cores, smaller source terms, passive safety features, enhanced release barriers, and reduced operating pressures. Analyses of many advanced reactor designs and attributes are expected to show that reactor accidents will (1) result in a significantly reduced source term and/or (2) limit any radioactive material fallout to within the site boundary or be limited to within a short distance of the EAB. Therefore, proposing a reduction in the source term, such as an order of magnitude, for advanced reactors seems appropriate. Such an approach would require each advanced reactor technology to demonstrate some minimum reduction in the source term to permit more liberal siting guidance in RG 4.7 for advanced reactor siting. The approach recommended is to revise the population density for advanced reactors to a value that is risk-neutral plus an accepted margin and to continue evaluating the density at the revised value out to 20 miles from the center of the reactor site. This reduction can be based on a comparison of the advanced reactor's thermal output to that of a standard size large LWR.

Alternatively, the population density analysis can be maintained at $500 \mathrm{ppsm}$ over the smaller radius swept out for the risk-neutral dose area without any added uncertainty margin. In the latter alternative, margin is effectively added by limiting the prospective dose to a smaller number of people. The resulting distance evaluation of the 10 CFR 100 requirement for a population center of 25,000 residents would provide more certainty for siting to advanced reactor vendors.

This approach would mirror the recent dose-based, consequence-oriented measure of the exemption efforts by the Tennessee Valley Authority (TVA) for their Clinch River site from certain emergency planning requirements using MELCOR Accident Consequence Code System. The TVA calculations include a composite source term for the collective designs under consideration plus a 25\% margin [55]. The staff concluded the following in the preliminary safety evaluation report [55]:

that the applicant has demonstrated that there are no physical impediments to the development of emergency plans for the proposed 2-mi plume exposure pathway emergency planning zone, as described in Early Site Permit Plan 5B and the Evacuation Time Estimate Report.

The connection of siting with impediments to emergency planning in the preceding staff conclusion can be found in 10 CFR 100.20(a), Factors to be Considered When Evaluating Sites:

(a) Population density and use characteristics of the site environs, including the exclusion area, the population distribution, and site-related characteristics must be evaluated to determine whether individual as well as societal risk of potential plant accidents is low, and that physical characteristics unique to the proposed site that could pose a significant impediment to the development of emergency plans are identified.

In SECY-16-0012, Accident Source Terms and Siting for Small Modular Reactors and Non-Light Water Reactors [56], the staff conclusively relates the emergency planning zone (EPZ), EAB, LPZ, the potential for reduced public dose (societal risk), and distance to a population center with at least 25,000 residents:

For example, future SMR applicants may be able to show that an individual at the EAB would not receive a dose that exceeds 1 rem TEDE within any 2-hour period of a release. This calculated dose is much lower than the current regulatory requirement that the dose not exceed 25 rem TEDE.

This results in the potential for the EAB and LPZ to be at the same distance around a very small site, potentially at a few hundred meters from the center of the reactor location or facility. The dose criteria which would allow for a smaller LPZ would also potentially allow the reactor to be considered for a location at a distance that is relatively close to a population center with at least 25,000 people. 
The DBA dose analyses performed by an applicant to show compliance with the siting safety analysis regulations and their related radiological releases to the environment are expected to be included in the spectrum of analyses that form the technical basis for the EPZ distance. Satisfying a 1 rem TEDE dose criterion for an EPZ of the same size as the $E A B$ and $L P Z$ would likely also demonstrate compliance by a large margin if compared with the 25 rem TEDE siting requirement in 10 CFR 50.34(a)(1)(ii)(D).

Another alternative is to structure the revised guidance for advanced reactors in a manner similar to that presented in NUREG-1537 for nonpower reactors. The NUREG-1537 guidance is simply to evaluate the population within a set distance (5 miles) from the reactor. No specific population density threshold is specified in the non-power reactor guidance. Such performance-based guidance may not be specific enough to provide consistent power reactor reviews. However, limiting the population evaluation distance to a significantly reduced value may have enough merit to provide technology vendors with a viable path forward for siting.

\section{DOE AND INDUSTRY (NUCLEAR ENERGY INSTITUTE [NEI]) INCENTIVES TO IMPROVE SITING CRITERIA}

DOE and industry stakeholders have looked into the possibility of using advanced reactor technology (SMRs, non-LWRs, and micro-reactors) to supply colocated, high-heat, industrial applications. Advanced reactors could serve as backfit technology to replace aging fossil-fuel electricity infrastructure. The implication of implementing these types of reactor applications implies siting NPPs closer to members of the general population. This section is intended to evaluate the potential benefit to advanced reactor vendors of any population and density changes to siting guidance.

\subsection{DO POSSIBLE GUIDANCE CHANGES IMPACT THE SITING OPPORTUNITY FOR ADVANCED REACTOR VENDORS?}

Oak Ridge National Laboratory (ORNL) maintains a geographic information system (GIS)-based tool to help evaluate power plant siting opportunities [57]. The tool, Oak Ridge Siting Analysis for power Generation Expansion (OR-SAGE), is a flexible system being used to merge industry-accepted approaches for screening sites with the array of GIS data sources at ORNL to identify candidate areas for a desired power plant application. One such GIS data source is population density drawn from the LandScan ${ }^{\mathrm{TM}}$ database, a high-resolution worldwide population distribution database developed by ORNL.

The OR-SAGE database partitions the contiguous United States, a total of 7.2E8 hectares ( 1.8 billion acres), into cells that measure $100 \times 100 \mathrm{~m}$ ( 1 hectare or $\sim 2.5$ acre $)$ cells. With this partitioning, the database tracks just under 700 million individual land cells. Using the current RG 4.7 guidance, the population density is evaluated for each individual cell. Each database cell is queried for ambient population, which considers the weighted transient population. If a cell population is greater than $500 \mathrm{ppsm}$, then it is immediately excluded. If a cell population is less than $500 \mathrm{ppsm}$, then the surrounding area is evaluated by calculating the population density in an expanding set of rings out to a maximum of 20 miles per the guidance in RG 4.7. If any ring is calculated to have a population density above $500 \mathrm{ppsm}$, then the cell under consideration is excluded. Cells on the edge of a population center will fail the population density criterion until the directional population back toward the urban center falls to a value that does not cause the total density within the entire 20 -mile radius to exceed $500 \mathrm{ppsm}$. If no ring around the central cell exceeds a population density of $500 \mathrm{ppsm}$, then the cell remains viable regarding population. This population density calculation is repeated for all 700 million cells in the 
database. This calculation can easily be adjusted to analyze different population densities or different calculation radii.

\subsubsection{OR-SAGE or Other Visual Reference}

The change in land that is potentially available for siting can be seen using several coal plant sites around Kansas City as an example. The selected coal plant sites represent a subset of all coal plants in the vicinity based on parameters used for a previous study [58].

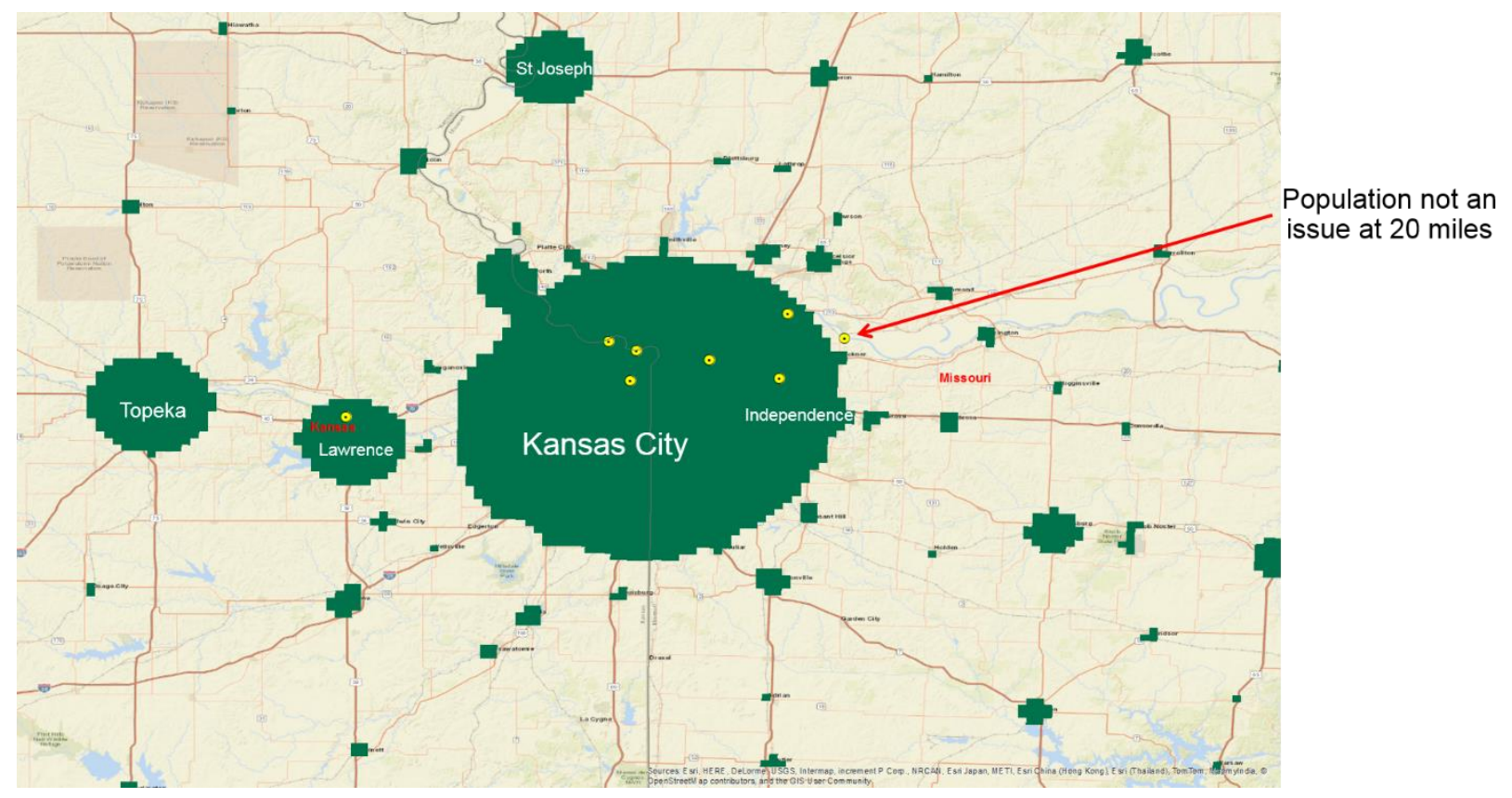

Figure 7. Excluded population density (500 ppsm at 20 miles).

The colored areas on the map in Figure 7 represent an area that is excluded based on exceeding 500 ppsm out to 20 miles. The yellow dots represent a select set of coal plant sites. As seen in Figure 7, only one of the selected plants meets the current RG 4.7 population density criterion. In Figure 8, the population density exclusion is reevaluated for $500 \mathrm{ppsm}$ out to $5 \mathrm{miles}$, and a second site becomes available for siting consideration. The results of a further reduction in the calculation for 500 ppsm out to 2 miles is shown in Figure 9, where multiple sites become available for siting consideration at this point. 


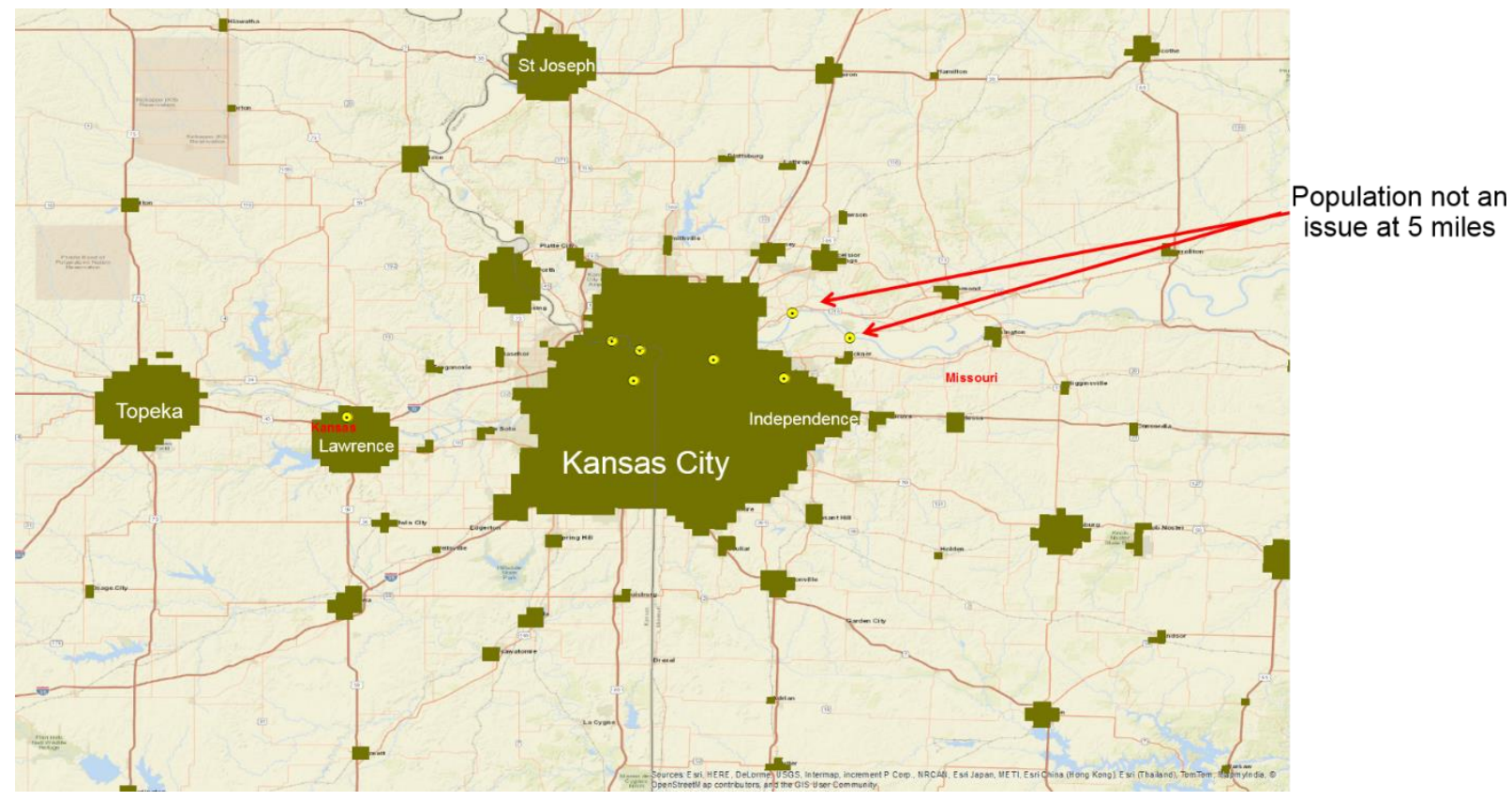

Figure 8. Excluded population density (500 ppsm at 5 miles).

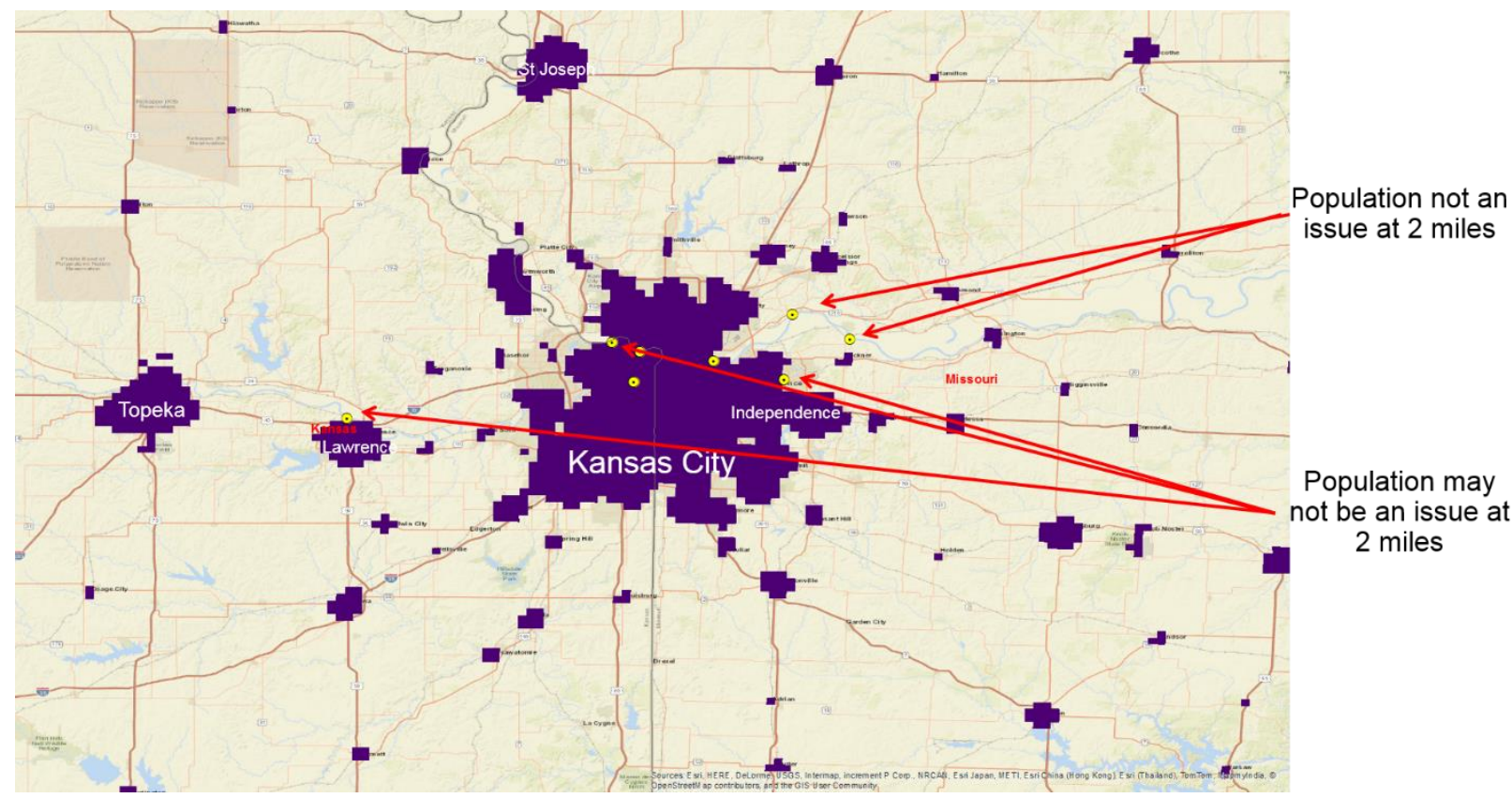

Figure 9. Excluded population density (500 ppsm at 2 miles).

The figures above represent the increased siting opportunities for one metropolitan area based on a limited set of coal plant sites. While the increased opportunity for utilizing coal plant sites to backfit an advanced reactor has not been calculated for any specific reduction in distance, it is apparent that the collective opportunity for advanced reactor vendors could be substantial. 


\subsubsection{Generic Sites of Interest}

Any fossil fuel plant site that is being phased out may be useful for advanced reactor siting. The existing infrastructure at such sites would have to match or bound the advanced reactor electrical output and cooling water demand, if applicable. The graphic in Figure 10 gives an idea of the number and location of coal plant sites from 2012. Although the landscape has changed since that time, there is certainly infrastructure available for consideration by advanced reactor vendors. In addition, Department of Defense sites, DOE sites, and industrial sites are available for advanced reactor siting.

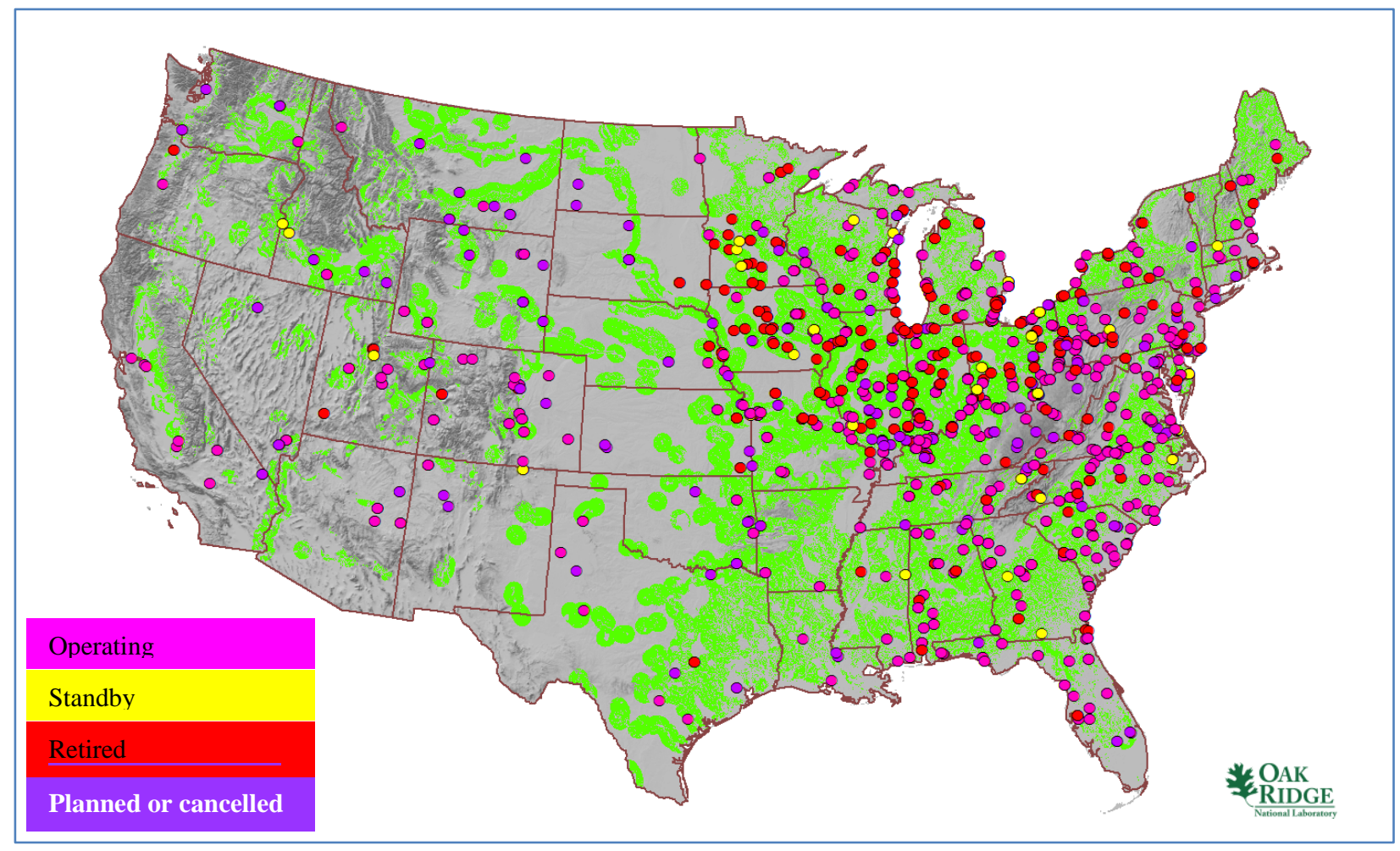

Figure 10. Coal plant sites as of 2012.

\subsection{USEFULNESS OF ALTERNATIVE CRITERIA IN ADDRESSING GOALS OF DOE, VENDORS, OR OTHER STAKEHOLDERS}

Using a single city as a proxy, Section 4.1 demonstrates the significance of reducing the distance required for making population density assessments (at $500 \mathrm{ppsm}$ ) around a proposed advanced reactor site.

Noteworthy tracts of land around and occasionally within heavily populated cities become available for consideration.

Although not visualized in this report, similar reductions in the size of areas excluded by population will also be evident if higher population density values are used instead of simply reducing the area over which the population density must be assessed. This is because the population density trip threshold for any given point around a population center will become higher, resulting in less area being excluded by population density.

As areas on the outskirts of population centers become available for siting, the potential for siting advanced reactors closer to the populations they will serve will increase. This is in line with the goals of DOE and economic considerations of vendors and their financiers to enact business plans that include 
siting reactors close to an industrial partner to supply heat or backfitting a reactor at a fossil plant site to take advantage of existing infrastructure.

\section{SUMMARY OF RESULTS/RECOMMENDATIONS}

This report describes considerations for and challenges to revising the NRC guidance regarding population for siting an advanced reactor. Current regulations in 10 CFR Part 100 and guidance support in RG 4.7, Revision 3 are focused on large LWRs. The regulations and guidance address the distance that a nuclear reactor should be sited away from a densely populated center. Some advanced reactor vendors use a business plan that sites SMRs, non-LWRs, and micro-reactors close to an industrial partner to supply heat or to back-fit a reactor at a municipal fossil plant site to take advantage of existing infrastructure. Factors that can positively impact a decision to site advanced reactors closer to densely populated centers than has historically been justified for large LWRs include smaller source terms, design attributes that eliminate or mitigate certain types of accidents, passive safety systems that initiate and operate without the need of operator action or other support systems, reactor design characteristics such as low operating pressures that minimize the driving force to spread fission products beyond engineered barriers, advances in barrier technology, advances in simulation and modeling, and better understanding of societal risk..

LWR operational data have accumulated over time, allowing for safety component and safety system reliability to be predicted more accurately with less uncertainty. In addition, better understanding of LWR fuel failure, coolant chemistry, aerosol behavior, accident progression, and failure timing have enabled better predictions of the timing and magnitude of fission product release from LWRs following severe accidents. Improved understanding of fission product releases following an accident coupled with advanced reactor attributes support the consideration of locating advanced reactors closer to population centers without any increased risk to the public.

Any revision to the siting guidance for advanced reactors must demonstrate that there is no increased risk to the public in the vicinity of a locally sited advanced reactor compared to a more remotely sited large LWR. The key for an advanced reactor design-independent approach is to make appropriate assumptions to bound the collective source term for advanced reactors. The original premise for siting large LWRs is based on very conservative assumptions regarding the large LWR accident source term and only considers the source term mitigation afforded by containment, The collective attributes of advanced reactor designs are expected to show that reactor accidents will (1) result in a significantly reduced source term and/or (2) limit any radioactive material fallout to within the site boundary or be limited to within a short distance of the EAB. Therefore, for cases in which advanced reactor attributes can be demonstrated to be bounded by some fractional source term value for most technologies relative to large LWRs, then this study proposes reducing the advanced reactor source term assumed by the siting guidance by a fraction based on reactor thermal output. A reduction of an order of magnitude in the societal risk ratio or more seems achievable. A reasonable basis for the source term reduction may be to ratio the advanced reactor thermal output to the thermal output of a standard large LWR $\left(3,000 \mathrm{MW}_{\text {th }}\right)$. The subsequent siting approach recommended is to revise the population density for advanced reactors to a value that is risk-neutral at the fractional source term value plus some margin and continue to evaluate the population density at the revised value out to 20 miles from the center of the reactor site. This approach can incorporate uncertainty margin and appears to provide the most direct comparison of effects to the current siting guidance for large LWRs.

A second alternative to the above recommendation for advanced reactor siting is to maintain the current population density evaluation at $500 \mathrm{ppsm}$. In this case, the $500 \mathrm{ppsm}$ density evaluation would be limited by the smaller area based on the reduced source term as described above. This approach takes advantage of the improved source term attributes of advanced reactors, limits the total area over which the 
population density at 500 ppsm must be considered, and effectively reduces the potential cumulative population dose relative to that of a large LWR.

A third alternative is to shift to a case-by-case, design-specific review of siting. Depending on the specific advanced reactor design, size of the core, safety systems, and land controlled by the operator, analyses may show that there are negligible onsite and offsite consequences following a reactor accident. Individual advanced reactor analyses can show that specific technologies can be sited very close to population centers with no undue risk to society and no sacrifice of current DID principles in play with current siting guidance. Review guidance for this alternative would be the most difficult to apply consistently, although the potential benefit to an applicant may be the greatest. 


\section{REFERENCES}

1. NRC, Siting Considerations Related to Population for Small Modular and Non-Light Water Reactors, Preliminary Draft, December 2017 (ML17333B158).

2. NRC, General Site Suitability Criteria for Nuclear Power Stations, RG 4.7, Revision 3, March 2014 (ML12188A053).

3. NRC, Metropolitan Siting - A Historical Perspective, NUREG-0478, October 1978 (ML12187A192).

4. NRC, Regulatory Impact of Nuclear Reactor Accident Source Term Assumptions, NUREG-0771, June 1981.

5. NRC, Technical Bases for Estimating Fission Product Behavior During LWR Accidents, NUREG0772, June 1981.

6. NRC, Development of Severe Reactor Accident Source Terms: 1957-1981 [PWR;BWR], NUREG0773, NRC, November 1982.

7. NRC, Assumptions Used for Evaluating the Potential Radiological Consequences of a Loss of Coolant Accident for Boiling Water Reactors, RG 1.3, Revision 2, June 1974 (ML003739601).

8. NRC, Assumptions Used for Evaluating the Potential Radiological Consequences of a Loss of Coolant Accident for Pressurized Water Reactors, RG 1.4, Revision 2, June 1974 (ML003739614).

9. NRC, Loss-of-Coolant Accidents Resulting from Spectrum of Postulated Piping Breaks within the Reactor Coolant Pressure Boundary, NUREG-0800, Section 15.6.5, March 2007 (ML070550016).

10. AEC, Calculation of Distance Factors for Power and Test Reactor Sites, TID-14844, March 23, 1962 (ML021720780).

11. D. Aldric et al., Technical Guidance for Siting Criteria Development, Sandia National Laboratory, NUREG/CR-2239, December 1982 (ML072320420).

12. NRC, Accident Source Terms for Light-Water Nuclear Power Plants, NUREG-1465, February 1995.

13. NRC, Alternate Radiological Source Terms for Evaluating Design Basis Accidents at Nuclear Power Plants, RG 1.183, July 2000 (ML003716792).

14. NRC, Issues Pertaining to the Advanced Reactor (PRISM, MHTGR, and PIUS) and CANDU 3 Designs and Their Relationship to Current Regulatory Requirements, SECY-93-0092, April 8, 1993 (ML003760774).

15. NRC Brochure, Modeling Potential Reactor Accident Consequences, November 2012 (ML12347A049).

16. IAEA, Innovative small and medium sized reactors: Design features, safety approaches and $R \& D$ trends, Final report of a technical meeting held in Vienna, 7-11 June 2004, IAEA-TECDOC-1451, May 2005.

17. M. Bowen, Enabling Nuclear Innovation Leading on SMRs, Nuclear Innovation Alliance, October 2017.

18. DOE Office of Nuclear Energy, What is a nuclear micro-reactor? October 23, 2018, www.energy.gov/ne/articles/what-nuclear-microreactor, accessed November 28, 2018.

19. Westinghouse Electric Company, Westinghouse eVinci ${ }^{\text {TM }}$ Micro Reactor, http://www.westinghousenuclear.com/New-Plants/eVinci-Micro-Reactor, accessed November 28, 2018. 
20. NRC Basic References, https://www.nrc.gov/reading-rm/basic-ref/glossary.html, accessed December $14,2018$.

21. NRC, Safety Goals for Nuclear Power Plants, NUREG-0880, Rev.1, May 1983 (ML071770230).

22. T. S. Kress, "Some thoughts on Defense-in-Depth," Presented to Regulatory Policies and Practices ACRS Subcommittee, August 27, 1997.

23. NRC, Historical Review and Observations of Defense-in-Depth, NUREG/KM-0009, April 2016 (ML16104A071).

24. International Atomic Energy Agency, Proposal for a Technology-Neutral Safety Approach for New Reactor Designs IAEA-TECDOC-1570, September 2007.

25. Nuclear Energy Institute, Risk-Informed Performance-Based Guidance for Non-Light Water Reactor Licensing Basis Development, NEI 18-04, Draft Report Revision N, September 2018.

26. NRC, Guidance for a Technology-Inclusive, Risk-Informed, and Performance-Based Approach to Inform the Content of Applications for Licenses, Certifications, and Approvals for Non-Light Water Reactors, Preliminary Draft Guide (DG-1353), September 2018.

27. GA Technologies, Probabilistic Risk Assessment for the Standard Modular High Temperature GasCooled Reactor, DOE-HTGR-86-011, Rev. 3, Vol. 1, January 1987.

28. Idaho National Laboratory, Next Generation Nuclear Plant Probabilistic Risk Assessment White Paper, INL/EXT-11-21270, September 2011.

29. G. F. Flanagan et al., A New Look at Licensing Basis Events for the Molten Salt Reactor Experiment, ORNL/TM-2018/788, Oak Ridge National Laboratory, August 2018.

30. NRC, Preapplication Safety Evaluation Report for the Power Reactor Innovative Small Module (PRISM) Liquid-Metal Reactor, NUREG-1368, February 1994 (ML063410561).

31. J. Gilleland, R. Petroski, and K. Weaver, "The Traveling Wave Reactor: Design and Development," Engineering 2, pp. 88-96, 2016.

32. C. Filippone and K. Jordan, "The Holos Reactor: A Distributable Power Generator with Transportable Subcritical Power Modules," engrXiv, June 2017.

33. NRC, Guidance for Developing Principal Design Criteria for Non-Light Water Reactors, RG 1.232, Revision 0, March 2018.

34. T. Sofu and G. F. Flanagan, "Module 5 - SFR Systems and Components," Presented at the Canadian Nuclear Safety Commission Information Seminar on Sodium Fast Reactors. December 10-11, 2018.

35. NRC, Staff Requirements - SECY-18-0096 - Functional Containment Performance Criteria for NonLight-Water-Reactors, Memorandum Dated December 4, 2018, December 2018 (ML18338A502).

36. NRC, Functional Containment Performance Criteria for Non-Light-Water-Reactors, SECY-18-0096, October 2018 (ML18114A546).

37. Westinghouse Electric Company, Next Generation Nuclear Plant: Plant Level Assessments Leading to Fission Product Retention Allocations, NGNP-PLD-GEN-RPT-N-00007, Revision 0, October 2009.

38. Idaho National Laboratory, Next Generation Nuclear Plant Defense-in-Depth Approach, INL/EXT09-17139, December 2009.

39. C. Beck, Engineering Study of Underground Construction of Nuclear Power Reactors, AECU-3779, United States Atomic Energy Commission, April 15, 1958. 
40. The Aerospace Corporation - Energy and Transportation Division, Evaluation of the Feasibility, Economic Impact, and Effectiveness of Underground Nuclear Power Plants, Final Technical Report, prepared for California Energy Commission, May 1978, pp. 1-10.

41. J. R. Buchanan, "Siting of Nuclear Facilities," selections from Nuclear Safety, ORNL/NUREG/NSIC118, p. 9.

42. C. W. Myers, Underground Nuclear Power Plants: Concepts, Advantages, and Issues, LA-UR-1101289, March 2011.

43. S. Pinto, A Survey of Underground Siting of Nuclear Power Plants, EIR-Bericht Nr. 382, December 1979, p. 1-17-1-23.

44. The Aerospace Corporation - Energy and Transportation Division, Evaluation of the Feasibility, Economic Impact, and Effectiveness of Nuclear Power Plants, Final Technical Report, prepared for California Energy Commission, May 1978, p. 2-1.

45. NRC, Guidelines for Preparing and Reviewing Applications for the Licensing of Non-Power Reactors: Format and Content, NUREG-1537, Part 1, February 1996 (ML042430055).

46. NRC, Guidelines for Preparing and Reviewing Applications for the Licensing of Non-Power Reactors: Standard Review Plan and Acceptance Criteria, NUREG-1537, Part 2, February 1996 (ML042430048).

47. NRC, Safety Evaluation Report Related to the Renewal of Facility Operating License No. TR-5 for the National Bureau of Standards Test Reactor, National Institute of Standards and Technology, Office of Nuclear Reactor Regulation, June 2009 (ML090990135).

48. AEC, Population Distribution around Nuclear Power Plant Sites, WASH-1308, April 1973 (ML100210453).

49. C. Starr. "Social Benefit versus Technological Risk." Science 165, no. 3899 (1969): pp. 1232-1238. http://www.jstor.org/stable/1727970.

50. NRC, An Assessment of Accident Risks in US Commercial Nuclear Power Plants, NUREG-75/014, WASH-1400, October 1975 (ML070600376).

51. NRC, Severe Accident Risks: An Assessment for Five U.S. Nuclear Power Plants, NUREG-1150 Vol. 1, December 1990 (ML120960691).

52. NRC, Report of the Siting Policy Task Force, NUREG-0625, August 1979 (ML12187A284).

53. A. Costa, Siting Considerations Related to Population for Small Modular and Non-Light Water Reactors, NRC, presented at NRC Public Meeting on Regulatory Improvements for Advanced Reactors, December 14, 2017 (ML17354B219).

54. NRC, Planning Basis for the Development of State and Local Government Radiological Emergency Response Plans in Support of Light Water Nuclear Power Plants, NUREG-0396, December 1978 (ML051390356).

55. M. Sutton, Letter to J. Rankin, "Summary Report for the Second Regulatory Audit of Clinch River Nuclear Site Early Site Permit Application - Part 6 Exemptions and Departures, Emergency Planning Exemptions," NRC, July 9, 2018 (ML18177A107).

56. NRC, Accident Source Terms and Siting for Small Modular Reactors and Non-Light Water Reactors, SECY-16-0012, February 2016.

57. G. T. Mays, R. J. Belles, O. A. Omitaomu, et al., Application of Spatial Data Modeling and Geographical Information Systems (GIS) for Identification of Potential Siting Options for Various Electrical Generation Sources, ORNL/TM-2011/157/R1, May 2012. 
58. R. J. Belles, O. A. Omitaomu, et al., Evaluation of Suitability of Selected Set of Coal Plant Sites for Repowering with Small Modular Reactors, ORNL/TM-2013/109, March 2013. 


\section{APPENDIX A. CURRENT SITING CRITERIA - REGULATIONS AND GUIDANCE}

Current NRC regulations and guidance related to siting criteria are principally addressed in 10 CFR 100, 10 CFR 50.34, 10 CFR 52.79, and RG 4.7. The IAEA also provides general nonbinding siting regulations and guidance. These documents provide current siting criteria, including population criteria, and they were principally developed based on large LWRs. A brief review of existing regulations and guidance is provided in this appendix for reference.

\section{A.1. SUMMARY OF REGULATIONS RELATED TO SITING}

Table A.1 summarizes the regulatory requirements related to siting and population distribution. 10 CFR 100 establishes the requirements for siting reactors applying for license under Part 50 or 52. Siting criteria are needed to ensure that public doses from normal operation and postulated accidents are "acceptably low" based on the "substantial knowledge base regarding power reactor design, construction, and operation." 10 CFR 50.34 and 10 CFR 52.79, Contents of Applications [Part 50 or Part 52] provide dose considerations for individuals on the $\mathrm{EAB}$ and the low population zone boundary.

Table A.1. Summary of siting-related regulations regarding population

\begin{tabular}{|c|c|c|}
\hline Regulations & Subject & Cited Material \\
\hline 10 CFR 100.3 & $\begin{array}{l}\text { Exclusion area } \\
\text { (EA) }\end{array}$ & $\begin{array}{l}\text {...that area surrounding the reactor, in which the reactor } \\
\text { licensee has the authority to determine all activities including } \\
\text { exclusion or removal of personnel and property from the area. } \\
\text {...Residence within the EA shall normally be prohibited... }\end{array}$ \\
\hline 10 CFR 100.3 & $\begin{array}{l}\text { Low population } \\
\text { zone (LPZ) }\end{array}$ & $\begin{array}{l}\text {...the area immediately surrounding the exclusion area } \\
\text { which contains residents, the total number and density of } \\
\text { which are such that there is a reasonable probability that } \\
\text { appropriate protective measures could be taken in their } \\
\text { behalf in the event of a serious accident. These guides do not } \\
\text { specify a permissible population density or total population } \\
\text { within this zone because the situation may vary from case to } \\
\text { case... }\end{array}$ \\
\hline 10 CFR 100.3 & $\begin{array}{l}\text { Population center } \\
\text { distance }\end{array}$ & $\begin{array}{l}\text {...the distance from the reactor to the nearest boundary of a } \\
\text { densely populated center containing more than about } \mathbf{2 5 , 0 0 0} \\
\text { residents. }\end{array}$ \\
\hline 10 CFR 100.20 & $\begin{array}{l}\text { Population density } \\
\text { and use } \\
\text { characteristics }\end{array}$ & $\begin{array}{l}\text { a. Population density and use characteristics of the site environs, } \\
\text { including the exclusion area, the population distribution, and } \\
\text { site-related characteristics must be evaluated to determine } \\
\text { whether individual as well as societal risk of potential plant } \\
\text { accidents is low, and that physical characteristics unique to the } \\
\text { proposed site that could pose a significant impediment to the } \\
\text { development of emergency plans are identified. }\end{array}$ \\
\hline 10 CFR 100.21 & $\begin{array}{l}\text { Non-seismic siting } \\
\text { criteria }\end{array}$ & $\begin{array}{l}\text { a. Every site must have an exclusion area and an LPZ. } \\
\text { b. The population center distance must be at least one and } \\
\text { one-third times the distance from the reactor to the outer } \\
\text { boundary of the LPZ... } \\
\text { h. Reactor sites should be located away from densely populated } \\
\text { centers. Areas of low population density are generally } \\
\text { preferred... }\end{array}$ \\
\hline
\end{tabular}




\begin{tabular}{|l|l|l|}
\hline Regulations & Subject & Cited Material \\
\hline $\begin{array}{l}\text { 10 CFR 50.34 } \\
\text { and }\end{array}$ & $\begin{array}{l}\text { Contents of } \\
\text { applications }\end{array}$ & $\begin{array}{l}\text { An individual located at any point on the boundary of the } \\
\text { exclusion area for any 2-hour period following the onset of } \\
\text { the postulated fission product release, would not receive a } \\
\text { radiation dose in excess of 25 rem total effective dose } \\
\text { equivalent (TEDE). }\end{array}$ \\
\hline $\begin{array}{l}\text { 10 CFR 50.34 } \\
\text { and }\end{array}$ & $\begin{array}{l}\text { Contents of } \\
\text { applications }\end{array}$ & $\begin{array}{l}\text { An individual located at any point on the outer boundary of } \\
\text { the LPZ, who is exposed to the radioactive cloud resulting from } \\
\text { the postulated fission product release (during the entire period } \\
\text { of its passage) would not receive a radiation dose in excess of 25 } \\
\text { rem TEDE. }\end{array}$ \\
\hline
\end{tabular}

\section{A.2. REGULATORY GUIDE 4.7 SITING}

Table A. 2 summarizes the regulatory guidance related to siting and population distribution. RG 4.7 describes an accepted method to implement nuclear plant siting requirements [1]. This regulatory guide fully describes the requirements set forth in 10 CFR 100, 10 CFR 50.34 and 52.79, as well as those in other environmental protection regulations as they are applied to nuclear plant siting. RG 4.7 provides considerable description about population and environmental concerns. RG 4.7 also specifies that transient population (i.e., those that work in but do not reside in, or those that are there temporarily for recreation or other activities, but not including those individuals just passing though) must also be included in the population density calculation.

Table A.2. Summary of siting-related guidance

\begin{tabular}{|l|l|l|}
\hline Guidance & Subject & Cited Material \\
\hline RG 4.7 & $\begin{array}{l}\text { Population } \\
\text { considerations - } \\
\text { population density }\end{array}$ & $\begin{array}{l}\text { A reactor should be located so that, at the time of initial plant } \\
\text { approval and within about 5 years thereafter, the population } \\
\text { density, including weighted transient population, averaged over } \\
\text { any radial distance out to 20 miles (cumulative population at a } \\
\text { distance divided by the circular area at that distance), does not } \\
\text { exceed 500 persons per square mile. A reactor should not be } \\
\text { located at a site where the population density is well in excess of } \\
\text { this value. }\end{array}$ \\
\hline & $\begin{array}{l}\text { Population } \\
\text { considerations - } \\
\text { DID }\end{array}$ & $\begin{array}{l}\text { Locating reactors away from densely populated centers is part of } \\
\text { the NRC DID philosophy and facilitates emergency planning } \\
\text { damage in the event of a severe accident. Numerical values in } \\
\text { this guide are generally consistent with past NRC practice and } \\
\text { reflect consideration of severe accidents, as well as the } \\
\text { demographic and geographic conditions characteristic of the } \\
\text { United States. }\end{array}$ \\
\hline
\end{tabular}

\section{A.3. INTERNATIONAL INSIGHTS}

The IAEA offers a forum for the development of nuclear safety fundamentals, safety requirements, and safety guidance. International consensus in these topical areas are documented in various report series and are available from the IAEA. These documents can be adopted and applied by member states as part of 
their regulatory infrastructure. While these documents have no regulatory status in the United States, they can provide insight into alternative experiences and best practices for various topics, including siting.

\section{A.3.1 IAEA Site Evaluations (IAEA NS-R-3) - Requirement}

The IAEA prepared safety standard NS-R-3, Site Evaluation for Nuclear Installations [2], to establish siting evaluation requirements for a nuclear installation. The requirements include analyzing the characteristics of the population in the region of the proposed nuclear facility. The generic population distribution requirements are tailored to the needs of a specific regulator:

\subsection{The distribution of the population within the region shall be determined.}

4.11. Information on existing and projected population distributions in the region, including resident populations and to the extent possible transient populations, shall be collected and kept up to date over the lifetime of the nuclear installation. The radius within which data are to be collected shall be chosen based on national practices. Special attention shall be paid to the population living in the immediate vicinity of the installation, to densely populated areas and population centers in the region.

4.13. The data shall be analyzed to give the population distribution in terms of the direction and distance from the nuclear installation. An evaluation shall be performed of the potential radiological impacts of discharges and accidental releases of radioactive material, including reasonable consideration of releases due to severe accidents, with the use of site-specific parameters as appropriate.

The requirements found in NS-R-3 mirror the requirements of 10 CFR 100 and the associated guidance provided by RG 4.7 without specifying specific distances to population centers and without specifically limiting population densities. The requirements provide for consideration of site-specific parameters in siting.

\section{A.3.2 IAEA Siting Recommendations (IAEA NG-T-3.7) - Guidance}

The IAEA prepared technical report NG-T-3.7, Managing Siting Activities for Nuclear Power Plants [3], "to provide guidance on siting issues related to management, technical, economic, environmental and social factors." Population density is named in the report as one of many unbounded siting criteria to be considered. Distance to population centers is noted to be a balance between the need for a power plant to be near supporting infrastructure (load centers, industry, labor pool, etc.) and remote enough to provide for the health and safety of the public.

\section{A.4. REFERENCES}

1. RG 4.7, Revision 3, General Site Suitability Criteria for Nuclear Power Stations, NRC, March 2014 (ML12188A053).

2. IAEA, Site Evaluation for Nuclear Installations, IAEA Safety Standards Series NS-R-3, Revision 1, February 2016.

3. IAEA, Managing Siting Activities for Nuclear Power Plants, IAEA Nuclear Energy Series NG-T-3.7, June 2012. 


\section{APPENDIX B. BRIEF HISTORY OF SITING CRITERIA}

\section{B.1 NEED FOR SITING CRITERIA}

The history provided in this appendix is drawn from material in NUREG-1610 [1].

The Atomic Energy Commission (AEC) was created in 1946 from the Atomic Energy Act (AEA). The AEA stipulated that civilian control be placed over the nation's nuclear weapons, with the government having a monopoly over nuclear technology for both civilian and military purposes. In 1954, amendments to the AEA allowed private industry to develop NPPs for electricity production. The AEC was tasked with protecting the health and safety of public from exposure to radionuclide releases from NPPs while also promoting the development of a new civilian nuclear industry. The combination of these two functions under the AEC spawned controversy and ultimately lead to the Energy Reorganization Act of 1974, which split the need for regulatory oversight from the promotion of the industrial development of nuclear energy within a single government agency.

Between 1954 and 1962, prior to the split in AEC roles, a variety of test and prototype reactors were developed, sited, and built, but there was a limited accumulation of commercial operating experience in any single reactor technology. For example, Fermi-I, a prototype liquid metal fast reactor developed by the Power Reactor Development Company in association with Detroit Edison, was built half-way between Detroit, Michigan, and Toledo, Ohio. It was the largest fast reactor developed at that time. Detroit Edison applied for a construction permit for the Enrico Fermi I plant in January of 1956. Concerns about siting and proximity to dense population areas were raised at the time, but these concerns did not dissuade the AEC from granting a construction permit in August of the same year.

Utilities like Detroit Edison desired power plants be sited close to metropolitan centers to minimize transmission costs. On the other hand, the Congressional Joint Committee on Atomic Energy (JCAE), established under the AEA to provide oversight on the AEC, recognized the potential risk this presented to the health and safety of the public. The JCAE pushed the AEC to develop a siting standard similar to the Boiler and Pressure Vessel Code (BPVC) developed by the American Society of Mechanical Engineers (ASME), which was modified for atomic pressure vessels between 1955 and 1963.

However, unlike ASME, the AEC did not have significant operating experience, nor did it possess substantial knowledge of the different hazards presented by the array of reactor technologies and the effectiveness of the proposed safeguards for each technology to construct a strong consensus siting standard like the ASME BVPC. As the number of reactor applications grew near population centers, uneasiness about a lack of consistent siting criteria grew.

\section{B.2 DEVELOPMENT OF SITING REGULATIONS}

Although the need for siting criteria was identified, the AEC hesitated to publish limits on licensing sites due to the complexities with the generalization of individualized safeguards, hazards, and other sitespecific features associated with each nuclear plant application. However, political forces ultimately forced the AEC to develop and publish siting criteria. Technical opinions on siting differed significantly among the established experts and compromise was necessary.

\section{B.2.1 Political Basis}

In 1948, the ACRS, which was organized in 1947 to advise the AEC, developed the first rule-of-thumb estimate of an exclusion area. The ACRS also introduced the concept of a hazard area just outside of the exclusion area where people could live based on the lower hazard (i.e., risk) to the public. However, they 
noted that any large or "industrially important" centers of population would still need to be excluded from this lower hazard area. The ACRS did not estimate what the size of this region should be due to the reactor design and site-specific features becoming more important as the hazard level or distance from the reactor increases.

Between 1948 and 1962, the AEC licensed plants on a case-by-case basis and did not use formal criteria or metrics for siting. The AEC opted instead to accept the utilities' and vendors' arguments for using a containment structure if there would be a "reasonable distance" between the reactor and major centers of population. The license applications for the Plum Brook 60 MW National Aeronautics and Space Administration (NASA) test reactor near Sandusky, Ohio, a BWR near Elk River, Minnesota, a BWR in Dresden, Illinois, Power Reactor Development Company's (PRDC's) Fermi I plant, and the Indian Point reactor just outside of New York City, challenged the AEC's concept of a "reasonable distance."

After the passage of the Price-Anderson Act in 1957, the ACRS was then required to review each reactor application. During the hearings and public meetings for these reactors, the ACRS expressed concerns over siting and other technical merits, such as not factoring in the probability of "maximum credible accidents" to the health and safety of the surrounding population. However, no new rules or conclusions on siting were drawn. The AEC licensed these sites primarily under the presumption that engineered safety features would provide adequate protection.

In 1959, as criticism of licensing more sites close to population centers increased, the AEC informally denied a reactor site in Jamestown, New York, for a small PWR. The Jamestown officials subsequently accused the AEC of baselessly rejecting their application by applying a double standard for siting. Fallout from this case, pressure from the JCAE, and continuing ACRS concerns over siting led to the creation of an AEC special working group on siting criteria led by Clifford Beck. Beck was the chief officer of the Hazards Evaluation Branch at the AEC and had previously worked on the Manhattan Project. Beck led the licensing of the first university research reactor at North Carolina State, and he created the first doctoral degree in nuclear engineering.

Beck and his team presented a first draft of their siting criteria to the ACRS in September of 1960. Over the subsequent two years, differences in technical opinions among the stakeholders and consideration for public comments were resolved. Following many meetings with the ACRS and other public and JCAE hearings, the AEC codified broad siting criteria within 10 CFR 100 in April 1962.

\section{B.2.2 Technical Basis}

The 1948 ACRS rule of thumb had many issues, but it was the first approach to quantify the risk as a function of distance from the reactor. At that time. the exclusion area, in miles from the reactor, was set at 0.01 times the square root of the thermal power of the reactor in $\mathrm{kW}$ [2]. This was reasonable for small reactors, but it became impractical as reactor thermal output increased. For example, a 1,000 $\mathrm{MW}_{\mathrm{e}}$ $\left(3,000 \mathrm{MW}_{\text {th }}\right)$ power plant would require an exclusion area radius of 17 miles. This estimate was based on an extremely conservative estimate that $50 \%$ of all fission products would be released as a cloud that spread out from the reactor. The exclusion area distance determined how far a person must be from an NPP to limit his or her whole-body dose to less than $300 \mathrm{rem}$. No new technical approaches or metrics to siting would be developed until the late 1950s.

In October of 1958, while reviewing the Elk River application and the doses associated with the maximum credible accidents, Beck theorized that anything over a 25-rem whole-body dose or a 200-rem thyroid dose over an 8-hour period would be of concern. Eight hours was defined as an appropriate amount of time for someone to escape a serious injury in the event of an accident if he or she were 
initially inside the exclusion area. Although population was initially sparse, population growth was also a siting concern for Elk River.

In January of 1959, Beck stipulated the following elements to the ACRS that he determined must be included for siting criteria: anticipated exclusion area distance, population density outside the exclusion area, site meteorology, seismology, hydrology, and geology. Exclusion area distance would be affected by the reactor's design features and safeguards such as containment, missile shields, and biological shields. Beck strongly suggested that proper emphasis be given to reactor design characteristics and safeguards.

In parallel to Beck's activities, the ACRS Environmental subcommittee was devising its own siting criteria based on quantitative estimates for dose. Beck disagreed with this philosophy, as he thought that the number of variables was too high to make an accurate estimate of expected releases and that it would take years to develop such an understanding. Beck countered this approach by suggesting that for small reactors (less than $100 \mathrm{MW}$ ), an exclusion area distance of one-quarter mile be used, and for large reactors, an exclusion area distance of one-half to three-quarter miles be used. The ACRS tabled both approaches and opened the debate to the wider industry.

There were many proposals from the industry, with no strong consensus. However, there was agreement that more research on siting was necessary. This led to the AEC concluding that guidelines should be proposed rather than establishment of a set of strict standards. Beck and the Environmental subcommittee continued to work toward agreement on a common set of criteria.

In September of 1960, Beck presented a draft set of basic siting criteria to the ACRS. Three benchmarks were proposed:

1. An exclusion area distance that is set by limiting the total whole-body dose of an individual to less than 25 rem or limiting the thyroid dose to less than 300 rem for the maximum credible accident. The 25-rem dose limit was set by the Radiation Council on Radiation Protection as the once-in-a-lifetime limit for radiation workers.

2. Establishing an evacuation area just outside of the exclusion area that is limited by the 25-rem whole-body/300-rem thyroid dose in consideration of any individual exposed over the entire time period of the maximum credible accident (integrated dose).

3. For any accident, not just the maximum credible accident, the population center, defined as $>25,000$ residents, should be $133 \%$ further away than evacuation distance.

Although the draft criteria were somewhat arbitrary with many conservative assumptions, Beck and his team suggested that the net effect would be a greater margin of safety than without such siting criteria in place.

The draft criteria were then presented to the AEC commissioners in December of 1960. Between the submittal and the final approval in 1962, several changes were adopted and are listed below:

- The evacuation area was relabeled as the low population zone (LPZ).

- References to maximum credible accident were eliminated.

- Example distance and expected dose calculations were eliminated. However, a supplemental information document, Technical Information Document (TID) 14844 [3], remained as the key reference for the criteria.

- The criteria were only applicable to power reactors and did not apply to research, test, or prototype reactors. 
- The criteria included discussion of locating multiple reactors on a single site.

This list is the initial siting criteria found in 10 CFR 100. When applying the new criteria to previously approved reactors such as Indian Point and Elk River, it was determined that those sites were well within the LPZ and population center distances and the exclusion area distances were roughly equivalent. Therefore, it was determined that the new criteria would not place an overabundance of regulatory safety burden on any new applications. Additionally, the new criteria would prevent potentially dangerous reactor designs from being placed too close to major populations. The intent was to strike a balance between site isolation and proximity to load centers [2]. Subsequent efforts were required to develop siting guidance to help an applicant meet the new siting criteria.

\section{B.3 DEVELOPMENT OF SITING GUIDANCE}

In 1973, the AEC published WASH-1308, Population Distribution around Nuclear Power Plant Sites [4], which began to formulate a policy for population density near a proposed NPP site. The policy recommendation noted that technology was available for engineered safety features to make siting in densely populated areas feasible from the standpoint of meeting the individual dose guidelines in 10 CFR Part 100. However, the AEC staff position was that operating experience data were not abundant, and offnormal and accident experience were lacking. This led to recommended policies that limit societal risk by promoting remote siting of NPPs (i.e., distance and population density). WASH-1308 proposed specific regulatory guidance to limit population density out to 40 miles to approximately $400 \mathrm{ppsm}$.

In 1974, the AEC drafted guidance for NPP site suitability [5] that included population guidance. The initial RG 4.7 guidance summarized previous thoughts on siting but lacked definitive population density numbers (ppsm) as suggested by WASH-1308. However, this RG 4.7 draft did provide a minimum exclusion area distance and a maximum required distance to the LPZ boundary:

Areas of low population density are preferred for nuclear power station sites. High population densities projected for any time during the lifetime of a station have been a source of contention during both the Regulatory staff review and the public hearing phases of the Licensing process, If the population density at a proposed site is not acceptably low, then the applicant will be required to give special attention to alternative sites with lower population densities.

Based on past experience, the Regulatory staff has found that a minimum exclusion distance of 0.4 mile, even with unfavorable design basis atmospheric dispersion characteristics, usually provides assurance that engineered safety features can be designed to bring the calculated dose from a postulated accident within the guidelines of 10 CFR Part 100. If the minimum exclusion distance is less than 0.4 mile, it may be necessary to place special conditions on station design (e.g., added engineered safety features) before the site can be considered acceptable. Also, based on past experience, the Regulatory staff has found that a distance of 3 miles to the outer boundary of the LPZ is usually adequate.

RG 4.7 was quickly revised in 1975 [6] to include a specific evaluation of population density out to 30 miles while retaining the previous guidance. The revision allowed consideration of up to 1,000 ppsm over the facility lifetime:

If the population density, including weighted transient population, projected at the time of initial operation of a nuclear power station exceeds 500 persons per square mile averaged over any radial distance out to 30 miles (cumulative population at a distance 
divided by the area at that distance), or the projected population density over the lifetime of the facility exceeds 1,000 persons per square mile averaged over any radial distance out to 30 miles, special attention should be given to the consideration of alternative sites with lower population densities.

In 1998, RG 4.7 was revised [7] to reflect the population guidance that is currently familiar to stakeholders. The guidance no longer includes a firm number for the minimum exclusion area distance and a minimum acceptable LPZ distance:

Preferably a reactor would be located so that, at the time of initial site approval and within about 5 years thereafter, the population density, including weighted transient population, averaged over any radial distance out to 20 miles (cumulative population at a distance divided by the circular area at that distance), does not exceed 500 persons per square mile. A reactor should not be located at a site whose population density is well in excess of the above value.

Therefore, distance and population density values have evolved over time. However, the original genesis of the values is based on containment as the only engineered safety feature and very conservative estimates of radioactivity release following a LWR LOCA.

\section{B.4 REFERENCES}

1. G. T. Mazuzan, and J. S. Walker, Controlling the Atom: The Beginnings of Nuclear Regulation 1946 - 1962, NUREG-1610, April 1997.

2. NRC, Metropolitan Siting - A Historical Perspective, NUREG-0478, October 1978 (ML12187A192).

3. AEC, Calculation of Distance Factors for Power and Test Reactor Sites, TID-14844, March 23, 1962 (ML021720780).

4. AEC, Population Distribution around Nuclear Power Plant Sites, WASH-1308, April 1973 (ML100210453).

5. NRC, General Site Suitability Criteria for Nuclear Power Stations, RG 4.7, Revision 0, September 1974 (ML13350A245).

6. NRC, General Site Suitability Criteria for Nuclear Power Stations, RG 4.7, Revision 1, November 1975 (ML13038A109).

7. NRC, General Site Suitability Criteria for Nuclear Power Stations, RG 4.7, Revision 2, April 1998 (ML003739894). 